Illinois State University

ISU ReD: Research and eData

Theses and Dissertations

$10-7-2015$

\title{
The effects of modafinil and atomoxetine on dopamine signaling in the striatal subregions of the rat
}

Martin Bobak

Illinois State University, bobak.martin47@gmail.com

Follow this and additional works at: https://ir.library.illinoisstate.edu/etd

Part of the Biology Commons, and the Neuroscience and Neurobiology Commons

\section{Recommended Citation}

Bobak, Martin, "The effects of modafinil and atomoxetine on dopamine signaling in the striatal subregions of the rat" (2015). Theses and Dissertations. 476.

https://ir.library.illinoisstate.edu/etd/476

This Thesis is brought to you for free and open access by ISU ReD: Research and eData. It has been accepted for inclusion in Theses and Dissertations by an authorized administrator of ISU ReD: Research and eData. For more information, please contact ISUReD@ilstu.edu. 


\title{
THE EFFECTS OF MODAFINIL AND ATOMOXETINE ON DOPAMINE SIGNALING IN THE STRIATAL SUBREGIONS OF THE RAT
}

\author{
Martin J. Bobak
}

\section{Pages}

In an effort to combat diseases and disorders that impede our health, comfort and well-being, an abundance of prescription drugs have emerged in the past 60 years. Many prescription drugs have remarkable efficacy for treating the primary symptoms of these diseases and disorders; however, some drugs carry negative side effects that impose their own adverse symptoms, albeit, often to a lesser degree than the primary symptoms. Thus, one of the main objectives of the pharmaceutical industry is to innovate and develop novel therapeutics, which remediate the primary symptoms of disease and lack undesirable negative side effects. However, in order to develop effective novel therapeutics, a comprehensive understanding of the underlying mechanisms of current drugs is critical. The work within this thesis investigates the mechanisms of two neuroactive drugs, which are commonly prescribed by physicians. Chapter I investigates modafinil (Provigil@), which is therapeutic for sleep and psychiatric disorders, and drug addiction therapy. Chapter II investigates atomoxetine (Strattera®), which is prescribed for attention deficit hyperactivity disorder (ADHD) and possesses limited abuse potential, 
in contrast to current ADHD medications, Adderall ${ }^{\circledR}$ and Ritalin ${ }^{\circledR}$, which are addictive. The effects of modafinil and atomoxetine on phasic dopamine signaling were investigated. Phasic dopamine signaling has been identified critical for reward learning and seeking, and is hypothesized to contribute to deficits in ADHD and drug addiction. The results herein suggest that alterations in phasic dopamine signaling are involved in the underlying mechanism of modafinil and atomoxetine action and may ultimately contribute to their therapeutic efficacy.

KEYWORDS: Dopamine, Fast-scan cyclic voltammetry, Modafinil, Atomoxetine, Narcolepsy, Attention deficit hyperactivity disorder, Phasic dopamine signaling 
THE EFFECTS OF MODAFINIL AND ATOMOXETINE ON DOPAMINE SIGNALING IN THE STRIATAL SUBREGIONS OF THE RAT

\author{
Martin J. Bobak
}

A Thesis Submitted in Partial Fulfillment of the Requirements for the Degree of

MASTER OF SCIENCE

School of Biological Sciences

\title{
ILLINOIS STATE UNIVERSITY
}


(C) 2015 Martin J. Bobak 
THE EFFECTS OF MODAFINIL AND ATOMOXETINE ON DOPAMINE SIGNALING IN THE STRIATAL SUBREGIONS OF THE RAT

Martin J. Bobak

COMMITTEE MEMBERS:

Paul A. Garris, Chair

Wolfgang Stein

Joseph M. Casto 


\section{ACKNOWLEDGMENTS}

First, I would like to thank my family for their constant support. A special thanks to my parents, Jancia and Bruno, for their encouragement throughout my whole time working towards my degree. Without their inspiring words, this process would have been much more difficult. Secondly, I would like to thank everyone whom I had worked with in the Garris lab. Never have I been surrounded by so many intelligent, hard-working, and driven individuals which have pushed me to new limits. I have adopted new philosophies and outlooks on hard-work, motivation, and perseverance which have helped me succeed here. I have the utmost respect to all those in this lab and wish nothing but success in their future. Lastly, I would like to thank Paul for all his patience, intelligence and words of encouragement during times of great difficulty, and especially for his guidance and advice on converting difficult obstacles into trivial ones.

M. J. B. 


\section{CONTENTS}

\section{Page}

ACKNOWLEDGMENTS $\quad$ i

CONTENTS

FIGURES $\quad$ iv

CHAPTER

I. MODAFINIL ACTIVATES PHASIC DOPAMINE SIGNALING IN THE DORSAL AND VENTRAL STRIATUM OF THE RAT 1

Abstract 2

Introduction 4

$\begin{array}{ll}\text { Materials and Methods } & 7\end{array}$

Animals $\quad 7$

Surgery $\quad 7$

Experimental Design $\quad 7$

Electrochemistry 8

Measurements with Electrical Stimulation $\quad 9$

Analysis of Dopamine Release and Uptake 9

Analysis of Basal Dopamine Levels and Dopamine Transients 9

Statistical Analysis $\quad 10$

$\begin{array}{ll}\text { Drugs } & 10\end{array}$

$\begin{array}{ll}\text { Results } & 12\end{array}$

Modafinil Robustly Increases the Amplitude of Electrically

Evoked Phasic-Like Dopamine Signals

Modafinil Increases Dopamine Release and Decreases Dopamine Uptake

Modafinil Has Negligible Effects on Basal Dopamine Levels 15

Modafinil Activates Dopamine Transients

Discussion

Modafinil Effects on Basal Dopamine Levels 
Modafinil Effects on Phasic Dopamine Signaling

References

\section{ATOMOXETINE ALTERS PHASIC DOPAMINE SIGNALING IN THE NUCLEUS ACCUMBENS OF THE RAT: A PRELIMINARY STUDY}

Abstract

Introduction

Methods and Materials

Animals

Surgery

Electrochemistry

Measurements with Electrical Stimulation

Results

Atomoxetine Inhibits Food-Pellet Consumption

Atomoxetine Diminishes Electrically Evoked Phasic-Like Dopamine Signals

Future Directions

References 


\section{FIGURES}

Figure $\quad$ Page

1. Schematic of Modafinil Effects on Dopamine Signaling 32

2. Representative Effects of Modafinil on Electrically Evoked Phasic-Like Dopamine Signals in the Dorsal and Ventral Striatum

3. Average Time Courses of Modafinil Effects on $[\mathrm{DA}]_{\max }$ in the Dorsal and Ventral Striatum

4. Qualitative Analysis of Dopamine Uptake on Electrically Evoked Phasic-Like Dopamine Signals

5. Effects of Modafinil on $[\mathrm{DA}]_{\max }$, Dopamine Release, and Dopamine Uptake

6. Path Analysis of Dose-Dependent Effects of Modafinil on [DA $]_{\max }$

7. Effects of Modafinil on Non-Electrically Evoked Dopamine Signals

8. Modafinil Effects on Dopamine Transients

9. Inverted-U Model of Attention Deficit Hyperactivity Disorder

10. Reinforcement Learning and Dopamine Function

11. Afferent Input and Midbrain Dopamine Neurons

12. Atomoxetine Decreases Amplitude of Electrically Evoked Phasic-Like Dopamine Signals

13. Atomoxetine Decrease Food-Evoked Dopamine Transients 


\section{CHAPTER I}

MODAFINIL ACTIVATES PHASIC DOPAMINE SIGNALING IN THE DORSAL AND VENTRAL STRIATUM OF THE RAT 


\section{ABSTRACT}

Modafinil (MOD) is a psychomotor stimulant exhibiting therapeutic efficacy for treating sleep, psychiatric disorders, and drug addiction. However, its mechanism of action is incompletely understood. Compared to other psychomotor stimulants inhibiting dopamine (DA) uptake, MOD weakly interacts with the dopamine transporter (DAT) and elicits lower elevations in dialysate DA in the striatum, suggesting additional MOD targets. However, the ability of MOD to induce wakefulness is abolished in DATknockout mice, suggesting that DAT is necessary for MOD action. Another pharmacologic target for psychomotor stimulants, but one not established for MOD, is the activation of phasic DA signaling. This mode of DA neuronal communication is implicated in reward learning and consists of burst firing of DA neurons generating rapid changes in extracellular DA termed transients. Here we investigated the effects of MOD on phasic DA signaling in the striatum of urethane-anesthetized rats with fast-scan cyclic voltammetry. We found that MOD (30-300 mg/kg i.p.) robustly increased the amplitude of electrically evoked phasic-like DA signals in a time- and dose-dependent fashion, with greater enhancement in the dorsal than ventral striatum. Analysis of these evoked signals to assess presynaptic mechanisms demonstrated that MOD also increases DA release and decreases DA uptake also in a time- and dose-dependent manner. Principal component regression of non-electrically evoked recordings revealed negligible changes in basal DA levels with high-dose MOD (300 mg/kg i.p.). Lastly, in the presence of the D2 DA antagonist, raclopride, to relieve anesthesia blunting of burst firing by DA neurons, lowdose MOD (30 mg/kg i.p.) robustly elicited DA transients in the dorsal and ventral striatum. Taken together, these results suggest that activation of phasic DA signaling is 
an important mechanism underlying the clinical efficacy of MOD. Figure 1 summarizes our findings. 


\section{Introduction}

Modafinil (MOD; Provigil $®)$ is a psychomotor stimulant exhibiting therapeutic efficacy for treating a variety of neuropathologies, including sleep-related disorders such as narcolepsy (Wise et al., 2007), obstructive sleep apnea syndrome (Pack et al., 2001), and shift-work sleep disorder (Czeisler et al., 2005), psychiatric disorders such as attention deficit hyperactivity disorder (ADHD) (Swanson et al., 2006) and schizophrenia (Ballon and Feifel, 2006), and drug addiction (Anderson et al., 2009; Shearer et al., 2009; Anderson et al., 2012). Similar to other psychomotor stimulants used therapeutically, such as amphetamine (Adderall@) and methylphenidate (Ritalin®), MOD enhances locomotor activity (Kuczenski et al., 1991; Edgar and Seidel, 1997; Kuczenski and Segal, 2001) and wakefulness (Wisor et al., 2001; Ishizuka et al., 2008), and exhibits cognitive enhancing properties (Barch and Carter, 2005; Kumar, 2008; Repantis et al., 2010). Indeed, a recent meta-analysis study has concluded that MOD can be used safely as a cognitive enhancer in normal, healthy subjects (Battleday and Brem, 2015). However, unlike other therapeutic psychomotor stimulants, MOD exhibits limited potential for abuse (Deroche-Gamonet et al., 2002). This attractive property has generated considerable interest in establishing the neuropharmacologic mechanism of MOD.

Although MOD has been found to modulate various neurotransmitters in the brain, including histamine, hypocretin (orexin), GABA, glutamate, norepinephrine, and serotonin, its effects on dopamine (DA) have received the greatest attention (Tanganelli et al., 1992; Ferraro et al., 1997a; Ferraro et al., 1997b; Chemelli et al., 1999; de Saint et al., 2001; Ishizuka et al., 2003). This atypical psychomotor stimulant appears to preferentially interact with the dopamine transporter (DAT), compared to the transporters 
for norepinephrine and serotonin, and to show little affinity for receptors for the monoamines and other neurotransmitters (Mignot et al., 1994; Madras et al., 2006; Zolkowska et al., 2009). However, whether MOD acts directly through DAT is controversial. On one hand, MOD exhibits weak affinity for DAT (Mignot et al., 1994; Madras et al., 2006; Zolkowska et al., 2009) and elicits only relatively modest increases in striatal dialysate DA (Ferraro et al., 1997b; Loland et al., 2012). On the other hand, MOD's effects appear to rely on DAT, as MOD-induced wakefulness is abolished in DAT-knockout mice (Wisor et al., 2001).

Based on work investigating actions of other DAT-inhibiting psychomotor stimulants, another potential target for MOD is phasic DA signaling. DA neurons signal in two distinct modes: tonic and phasic (Grace and Bunney, 1984a; Grace and Bunney, 1984b). Slow, irregular firing of DA neurons generates a basal extracellular level of DA called tone during tonic DA signaling, whereas burst firing of DA neurons generates rapid increases in extracellular DA called transients during phasic DA signaling (Grace and Bunney, 1984a; Sombers et al., 2009). Phasic DA signaling is involved in reward learning (Schultz et al., 1997; Day et al., 2007) and seeking (Phillips et al., 2003b), and alterations in phasic DA signaling are hypothesized to contribute to ADHD (Tripp and Wickens, 2008) and drug addiction (Covey et al., 2014). Several DAT-inhibitor psychomotor stimulants have been shown to activate phasic DA signaling by increasing burst firing of DA neurons (Shi et al., 2000; Shi et al., 2004; Koulchitsky et al., 2012) and the frequency of DA transients in the striatum (Venton and Wightman, 2007; Covey et al., 2013; Daberkow et al., 2013). DAT-inhibiting psychostimulants have also been shown to act presynaptically to enhance DA release in addition to inhibiting DA uptake 
(Wu et al., 2001a; Venton et al., 2006; Chadchankar and Yavich, 2012). Whether MOD acts similarly to activate phasic DA signaling has not been examined.

Here we use fast-scan cyclic voltammetry (FSCV) at a carbon-fiber microelectrode (CFM) to investigate the effects of MOD on phasic DA signaling in urethane-anesthetized rats. The effects of MOD were examined in the dorsal and ventral striatum across a wide behaviorally relevant range of doses (30 - $300 \mathrm{mg} / \mathrm{kg}$ i.p.) (Edgar and Seidel, 1997; Beracochea et al., 2001; Ward et al., 2004). Two measures of phasic DA signaling were assessed: the amplitude of electrically evoked phasic-like DA signals and DA transients elicited in the presence the D2 DA antagonist, raclopride, to overcome anesthesia blunting of burst firing by DA neurons (Shi et al., 2000; Shi et al., 2004; Venton and Wightman, 2007). In addition, the effects of MOD on the presynaptic mechanisms of DA release and uptake (Wu et al., 2001b) and on tonic DA levels as analyzed using principle component regression (PCR) (Keithley et al., 2009) were also determined. Taken together, our results suggest that activation of phasic DA signaling is a novel mechanism contributing to the therapeutic efficacy of MOD. 


\section{Materials and Methods}

Animals. Male Sprague-Dawley rats (300-400 g) were purchased from Harlan (Indianapolis, IN, USA) and housed in a temperature-controlled vivarium on a diurnal light cycle (12h light/dark) with food and water provided ad libitum. Animal care conformed to the NIH Guide for the Care and Use of Laboratory Animals and experimental procedures were approved by the Institutional Animal Use and Care Committees at Illinois State University.

Surgery. Rats were anesthetized with urethane $(1.6 \mathrm{~g} / \mathrm{kg}$, i.p. $)$ and immobilized in a stereotaxic frame (David Kopf Instruments, Tujunga, CA, USA). Holes for reference, stimulating, and two CFMs were drilled. All coordinates, anteroposterior (AP), mediolateral (ML) and dorsoventral (DV), are given in $\mathrm{mm}$ and are referenced to bregma (Paxinos and Watson, 1986). The stimulating electrode targeted the medial forebrain bundle (MFB; -4.6 AP, +1.3 ML, -7.5 DV). CFMs targeted the dorsal (+1.2 AP, +3.0 $\mathrm{ML},-4.5 \mathrm{DV})$ and ventral (+1.2 AP, +1.5 ML, -6.5 DV) striatum. The $\mathrm{Ag} / \mathrm{AgCl}$ reference electrode was placed in the contralateral superficial cortex.

Experimental Design. DA was recorded in sequential 5-minute epochs and for most recordings, FSCV was performed simultaneously at separate CFMs implanted in the dorsal and ventral striatum of a single animal. In the first experimental design, four predrug and 30 post-drug epochs were collected, and electrical stimulation of the MFB was applied 5 seconds into each epoch. The effects of vehicle (2-hydroxypropyl)- $\beta$ cyclodextrin (vehicle) or MOD (30,60, 100 or $300 \mathrm{mg} / \mathrm{kg}$ ) were examined on electrically evoked DA signals for the entire duration of DA measurements (15 min pre-drug and 160 min post-drug. The effects of vehicle or MOD across the same dose range as above on 
DA release and uptake were examined pre-drug and at 30 and 60 min post-drug. The effects of vehicle or high-dose MOD $(300 \mathrm{mg} / \mathrm{kg})$ on changes in basal DA levels were examined pre-drug for $40 \mathrm{~min}$ post-drug. In the second experimental design, electrical stimulation was applied pre-drug and every 30 min post-drug to assess the veracity of the CFM. After pre-drug recordings, raclopride (2 mg/kg) was co-administered with lowdose MOD $(30 \mathrm{mg} / \mathrm{kg})$ and DA transients were analyzed during 5-min epochs pre-drug and post-drug at 15, 30, 60 and $120 \mathrm{~min}$. All vehicle and drugs were administered intraperitoneally (i.p.) in a total volume of $2 \mathrm{ml} . \mathrm{n}=4-7$ each in the dorsal and ventral striatum.

Electrochemistry. DA measurements were recorded with FSCV at a CFM by applying a triangular waveform ( -0.4 to $+1.3 \mathrm{~V}$ and back) at a rate of $400 \mathrm{~V} / \mathrm{s}$ every 100 ms. CFMs were fabricated by aspirating a single carbon fiber $(r=3.55 \mu$ m; HexTow AS4, HexCel Corp., Stamford, CT, USA) into a borosilicate capillary tube (1.2mm o.d.; Sutter Instrument, Novato, CA, USA) and pulling to a taper using a micropipette puller (Narishige, Tokyo, Japan). The carbon fiber was then cut to $\sim 100 \mu \mathrm{m}$ distal to the glass seal. FSCV was performed by a Universal Electrochemistry Instrument (UEI; Department of Chemistry Electronic Shop, University of North Carolina, Chapel Hill, NC, USA) and commercially available software (ESA Bioscience, Chelmsford, MA, USA). Current recorded at peak oxidative potential for DA $(\sim+0.6 \mathrm{~V})$ was converted to DA concentration based on post-calibration of the CFM using flow-injection analysis in a modified TRIS buffer (Kume-Kick and Rice, 1998; Wu et al., 2001b; Phillips et al., 2003a). DA was initially identified from the background subtracted voltammogram (Michael et al., 1998; Heien et al., 2004). 
Measurements with Electrical Stimulation. Electrical stimulation was computer generated and passed through an optical isolator and constant-current generator (Neurolog NL800; Digitimer Limited, Letchworth Garden City, UK). Biphasic stimulation pulses were applied to a twisted bipolar electrode (Plastics One, Roanoke, VA, USA), with tips separated $\sim 1 \mathrm{~mm}$. Stimulus parameters were $\pm 300 \mu \mathrm{A}$ intensity and 4 ms biphasic pulses ( $2 \mathrm{~ms}$ each phase), trains were applied at a frequency of $60 \mathrm{~Hz}$ for $0.4 \mathrm{~s}$.

Analysis of Dopamine Release and Uptake. Electrically evoked phasic-like DA signals were analyzed to determine maximal amplitude ([DA $\left.]_{\max }\right)$ and parameters for presynaptic DA release and uptake according to (Wightman et al., 1988; Wu et al., 2001b):

$$
\text { [1] } \mathrm{d}[\mathrm{DA}] / \mathrm{dt}=[\mathrm{DA}] \mathrm{p} * \mathrm{f}-\mathrm{k}[\mathrm{DA}]
$$

where $[\mathrm{DA}]_{\mathrm{p}}$ is the concentration of DA elicited per stimulus pulse used to index DA release, $\mathrm{k}$ is the first-order rate constant for DA uptake, and $\mathrm{f}$ is the frequency of electrical stimulation. $[\mathrm{DA}]_{\mathrm{p}}$ and $\mathrm{k}$ were determined by fitting data to equation 1 using a nonlinear regression with a simplex-minimization algorithm (Wu et al., 2001b). Temporal distortion in measured DA responses was accounted for using a diffusion gap model, with the width held constant for each CFM across pre- and post-drug measurements (Wu et al., 2001b).

Analysis of Basal Dopamine Levels and Dopamine Transients. Changes in nonelectrically evoked DA levels were assessed using PCR to resolve DA, pH, and background drift from FSCV recordings (Hermans et al., 2008; Keithley et al., 2009). In select files, PCR additionally resolved a repetitive background noise component. PCR 
analysis was accepted if any current in the recordings not accounted for by the retained principal components of the training sets, or residual (Q), was less than the $95 \%$ confidence threshold $\left(\mathrm{Q}_{\alpha}\right)$. Epochs where $\mathrm{Q}$ exceeded $\mathrm{Q}_{\alpha}$ were not used for analysis. Changes in baseline DA levels $(\Delta[\mathrm{DA}])$ per 5 min-epoch were determined by averaging all data points post-stimulation of PCR-resolved traces. Data are presented as $\Delta[\mathrm{DA}]$ within each five-minute epoch and not as a contiguous concatenation to avoid resetting Q with a new background subtraction at the start of each epoch. DA transients were identified in PCR-resolved traces as peaks greater than 5-times the root-mean-squarenoise using peak-finding software (MINI ANALYSIS; Synaptosoft, Decatur, GA, USA). Statistical Analysis. Where appropriate, data are expressed as the mean \pm SEM. Unless noted below, statistical analyses were performed with SAS version 9.3 (SAS Institute). Time courses for $[\mathrm{DA}]_{\max },[\mathrm{DA}]_{\mathrm{p}}$, and $\mathrm{k}$ were analyzed using a three-way ANOVA with repeated measures with time, drug dose, and striatal region as factors. Path analysis was conducted to assess the direct and indirect influences of $[\mathrm{DA}]_{\mathrm{p}}$ and $\mathrm{k}$ on dose-dependent effects of MOD on $[\mathrm{DA}]_{\max }$. Alternative path analyses were conducted to compare Akaike Information Criteria (AIC) of reduced models to those of the complete model. A two-way ANOVA with repeated measures assessed differences in DA transient frequency with time and dose as factors. Correlations were performed with Sigma Plot 12.0 (Systat Software Inc., San Jose, CA, USA). Significance was set at p $<0.05$.

Drugs. Urethane, (2-hydroxypropyl)- $\beta$-cyclodextrin and raclopride were purchased from Sigma (St. Louis, MO, USA). MOD was provided by Research Triangle InstituteNational Institute on Drug Abuse, Raleigh, NC. Urethane and raclopride were dissolved 
in $150 \mathrm{mM} \mathrm{NaCl}$ prior to injection. MOD was dissolved in a mixture of 50\% (2hydroxypropyl)- $\beta$-cyclodextrin and nanopure $w / v$. 


\section{Results}

\section{Modafinil Robustly Increases the Amplitude of Electrically Evoked Phasic-Like}

Dopamine Signals. Figure 2 shows representative effects of MOD on electrically evoked phasic-like DA signals collected in the dorsal (Fig. 2A) and ventral (Fig. 2B) striatum. In the top of each panel, electrical stimulation of MFB increased [DA] as measured by FSCV at a CFM. Pseudo-color plots below, which serially display all voltammograms collected during the recording, and individual voltammograms (inset) identify DA as the primary analyte recorded based on the electrochemical profile. MOD (100 mg/kg) increased $[\mathrm{DA}]_{\max }$ in both the dorsal and ventral striatum 60 minutes post-drug administration.

Figure 3 shows averaged time courses of MOD effects on $[\mathrm{DA}]_{\max }$ expressed as a percent change from pre-drug in the dorsal (Fig. 3A) and ventral (Fig. 3B) striatum. All four doses, 30, 60, 100, $300 \mathrm{mg} / \mathrm{kg}$ MOD, appeared to elevate [DA $]_{\max }$ compared to vehicle control for more than 2.5 hours post-drug administration. Consistent with representative recordings shown in figure 2 , averaged MOD appeared to elevate $[\mathrm{DA}]_{\max }$ to a greater extent in the dorsal than in the ventral striatum. A three-way repeated measures ANOVA revealed significant effects of time $(\mathrm{F} 33,1419=30.83, \mathrm{p}=<0.0001)$, dose $(\mathrm{F} 4,43=15.47, \mathrm{p}=<0.0001)$, and region $(\mathrm{F} 1,43=5.85, \mathrm{p}=<0.0198) ;$ thus, MOD increased $[\mathrm{DA}]_{\max }$ in a time- and dose-dependent manner with a greater effect in the dorsal striatum. There were also significant time-by-dose $(\mathrm{F} 132,1419=9.04, \mathrm{p}=$ $<0.0001)$ and time-by-region $(\mathrm{F} 132,1419=4.17, \mathrm{p}=0.0207)$ interactions but no regionby-dose interaction $(\mathrm{F} 4,43=0.70, \mathrm{p}=<0.5970)$. 
Modafinil Increases Dopamine Release and Decreases Dopamine Uptake. MODinduced increases in $[\mathrm{DA}]_{\max }$ could be mediated by enhanced DA release and/or inhibited neuronal DA uptake. To initially assess whether MOD decreased DA uptake, electricallyevoked decay curves were overlaid at the same concentration (Fig. 4 inset) and the slopes were visually inspected between pre- and post-drug traces. The downward slope of the evoked trace is thought to be due to DA uptake and not DA release (Wu et al., 2001b). Thus, the flatter post-drug traces after MOD indicates slower DA clearance from the extracellular space (Fig. 4). This qualitative approach suggests that MOD appears to decrease DA uptake, suggesting that the increase in $[D A]_{\max }$ may be DA uptake inhibition, at least in part. However, MOD-induced increases in DA release may also play a role, because the upward slope of the evoked trace is due to the balance of DA release and uptake (Wu et al., 2001b).

To quantitatively resolve MOD's effect on DA release and uptake on [DA $]_{\max }$, electrically evoked responses were fit to Eq. 1. Figure 5 shows [DA $]_{\max }$ (left), DA release as indexed by $[\mathrm{DA}]_{\mathrm{p}}$ (middle), and DA uptake as indexed by $\mathrm{k}$ (right) for the dorsal (Fig. 5A) and ventral (Fig. 5B) striatum. Three time points were assessed: pre-drug, $30 \mathrm{~min}$, and $60 \mathrm{~min}$. Three-way repeated measures ANOVA was used for statistical analysis for each parameter. Statistical analysis of $[\mathrm{DA}]_{\max }$ revealed significant effects of time (F2, 88 $=60.28, \mathrm{p}=<0.0001)$, dose $(\mathrm{F} 4,44=3.47, \mathrm{p}=0.0151)$, and time-by-dose interaction $(\mathrm{F} 8,88=15.59, \mathrm{p}=<0.0001)$ but no significant effect of region $(\mathrm{F} 1,44=2.79, \mathrm{p}=$ 0.1022). The nonsignificant regional effect in this analysis was most likely attributed to the reduced number of time points examined at maximal drug (>60 $\mathrm{min}$ ) as compared to the complete time course in figure 3 . Analysis of $[D A]_{p}$ revealed significant effects of 
time $(\mathrm{F} 2,88=37.48, \mathrm{p}=<0.0001)$, dose $(\mathrm{F} 4,44=3.30, \mathrm{p}=0.0189)$, and time-by-dose interaction $(\mathrm{F} 8,88=9.23, \mathrm{p}=<0.0001)$ but no significant effect of region $(\mathrm{F} 1,44=0.18$, $\mathrm{p}=0.6774)$. Finally, analysis of $\mathrm{k}$ revealed significant effects of time $(\mathrm{F} 2,88=56.82, \mathrm{p}=$ $<0.0001)$ and region $(\mathrm{F} 1,44=7.72, \mathrm{p}=0.008)$, as well as a time-by-dose interaction $(\mathrm{F} 8$, $88=3.82, \mathrm{p}=0.0023)$. Taken together, these results demonstrate that MOD increases DA release and decreases DA uptake in a time-dependent fashion.

We next used path analysis to evaluate the respective contribution of increased DA release and decreased DA uptake to the dose-dependent effects of MOD on [DA $]_{\max }$ in order to gain more insight into whether one of these presynaptic mechanisms is preferentially targeted. Path analysis is a statistical technique that tests effects of multiple independent variables on a dependent variable, much like multiple regression; however, path analysis allows for the possibility that variables can be both dependent and independent (i.e., variables can be both affected by dose and affect other variables). The output of path analysis, path coefficients, are standardized regression coefficients and indicate the strength and direction (i.e., positive or negative) of the relationship between the variables.

Figure 6 shows the complete model for path analysis, with arrows demarcating direct relationships between variables and the path coefficient given above each arrow. Path analysis of the complete model suggests that MOD dose exerts an almost equal, but opposite, direct effect on DA release (+0.6359) and uptake (-0.6571); thus, increasing the dose of MOD increases DA release and decreases DA uptake to a similar magnitude. However, DA release exerted a greater effect on $[\mathrm{DA}]_{\max }$ as compared to DA uptake, +0.9192 and -0.1423 respectively, suggesting that DA release was preferentially targeted 
by MOD to increase $[\mathrm{DA}]_{\max }$. Based on $95 \%$ confidence intervals, the effect of MOD dose on DA release (95\% confidence interval, $0.48-0.80$ ) and uptake (95\% confidence interval, $0.50-0.81$ ) was not significantly different but that the effect of DA release (95\% confidence interval, $0.88-0.96$ ) on [DA $]_{\max }$ was significantly greater than that of DA uptake (95\% confidence interval, 0.09-0.20). Lastly, path analyses for alternative models (i.e., omitting either DA uptake or release) were conducted, and AIC values between were compared to determine which model was most appropriate. Omitting DA uptake or DA release resulted in increased AIC, (44 and 196 respectively), as compared to the original model (19), which included both parameters, suggesting that both DA release and uptake together best explain the MOD dose effects on [DA $]_{\max }$ as compared to individually. Additionally, the larger AIC calculated after omission of DA release, as compared to DA uptake, suggests that when DA release is omitted the model has a weaker fit, which is consistent with path coefficients derived for the complete model.

Modafinil Has Negligible Effects on Basal Dopamine Levels. MOD effects on basal DA levels were assessed by applying a chemometrics analysis technique termed PCR (Hermans et al., 2008; Keithley et al., 2009) to the non-electrically evoked portion of the raw FSCV recording. Figure 7A shows representative FSCV and PCR recordings for pre-drug and 60 minutes post-300 mg/kg MOD, the highest dose tested. The raw FSCV recording (top; black trace) shows a steady increase in current for both pre- and post-drug conditions (left and right, respectively). However, the current cannot be attributed solely to DA as the color plot below shows additional electrochemical changes not attributed to DA. Furthermore, the voltammogram (inset) contains other analytes (blue) that would mask changes in DA (black) if present. PCR resolves DA from these 
interferents and these representative traces resolved by PCR (red) suggest negligible changes in basal DA levels with MOD.

To assess MOD-induced changes in basal DA levels within individual 5 minepochs ( $\Delta[\mathrm{DA}])$, all data points in PCR resolved DA files after the electrically evoked response returned to baseline were averaged pre-drug and for the first $40 \mathrm{~min}$ of drug response. The time period was selected to examine the initial effects of MOD on basal extracellular DA corresponding to the initial robust increase in electrical evoked phasiclike DA signals (Fig. 3). Time 0 min was excluded because of noise introduced during drug administration. MOD had negligible effects on $\Delta[\mathrm{DA}]$ (Fig. 7B) in either the dorsal (top) or ventral (bottom) striatum. The three-way repeated measures ANOVA revealed no significant effect of time $(\mathrm{F} 10,90=1.80, \mathrm{p}=0.1764)$, dose $(\mathrm{F} 1,9=0.11, \mathrm{p}=0.7433)$, or region $(F 1,9=0.47, p=0.5118)$, indicating that there was no significant effect of MOD on basal DA levels. Additionally, there were no significant interactions.

To verify PCR selectivity for the DA component, a linear regression was performed between $[\mathrm{DA}]_{\max }$ from raw FSCV recordings ([DA $\left.]_{\mathrm{FSCV}}\right)$ and PCR-resolved data $\left([\mathrm{DA}]_{\mathrm{PCR}}\right)$. The current attributed to the electrically-evoked response measured in the FSCV trace over short time scales has previously been described to be primarily DA (Wightman et al., 1986). Thus, the tight association of data points to the trend line and significant correlation between $[\mathrm{DA}]_{\mathrm{FSCV}}$ and $[\mathrm{DA}]_{\mathrm{PCR}}$ in both the dorsal $($ Fig. $7 \mathrm{C}$ left; $\mathrm{r}=$ 0.8901, $\mathrm{p}<0.0001$ ) and ventral (Fig. 7C right; $\mathrm{r}=0.9639, \mathrm{p}<0.0001$ ) striatum suggests that PCR accurately resolved DA from the mixed analyte signal. 
Modafinil Activates Dopamine Transients. Under anesthesia, DAT-inhibiting psychomotor stimulants exert an inhibitory effect on DA neuron firing (Shi et al., 2000; Shi et al., 2004), yet an excitatory action in freely behaving rats (Koulchitsky et al., 2012). Co-administration of a DA D2 receptor antagonist alleviates the blunting effects produced under anesthesia, allowing these DAT-inhibitors to elicit burst firing of DA neurons (Shi et al., 2000; Shi et al., 2004) and DA transients (Venton and Wightman, 2007) under these conditions. Similar to other DAT-inhibiting psychomotor stimulants, co-administration of MOD $(30 \mathrm{mg} / \mathrm{kg})$ and raclopride $(2 \mathrm{mg} / \mathrm{kg})$, a DA D2 receptor antagonist, induced DA transients in both the dorsal (Fig. 8A left) and ventral (Fig. 8A right) striatum. Asterisks demark transients on the FSCV current trace taken at the peak DA oxidation potential. Transients were confirmed to be DA by the electrochemical profile in the pseudo-color plot and comparison of the individual transient voltammograms (inset, red) to electrically evoked DA voltammograms (inset, black). Prior to assessing transient frequency at select time points, DA in the FSCV traces was resolved with PCR. As shown in figure 8B, there were no transients pre-drug, which sharply contrasts the robust increase in transient frequency 15 minutes post-drug administration and after. A two-way repeated measures ANOVA revealed a significant effect of time on transient frequency $(\mathrm{F} 3,27=11.85, \mathrm{p}=<0.0001)$. However, there were no significant effects of region $(\mathrm{F} 1,9=0.18, \mathrm{p}=0.6835)$ or a significant time-by-region interaction $(\mathrm{F} 3,27=1.72, \mathrm{p}=0.1932)$. 


\section{Discussion}

Here we demonstrate using FSCV at a CFM in the anesthetized rat that MOD activates phasic DA signaling in both the dorsal and ventral striatum without altering basal DA levels. The activation of phasic DA signaling was indicated by an increase in the amplitude of electrically evoked phasic-like DA signals and the frequency of DA transients assessed in the presence of the DA D2 antagonist, raclopride. MOD additionally acted presynaptically to increase DA release and decrease DA uptake, although the former action contributed to a greater extent to the increase in evoked DA signal. Taken together, the results suggest that activation of phasic DA signaling is a novel mechanism of MOD that may contribute to its therapeutic efficacy.

Modafinil Effects on Basal Dopamine Levels. In the current study, PCR revealed no significant changes in basal DA levels in either the dorsal or ventral striatum after administration of the highest dose of MOD tested $(300 \mathrm{mg} / \mathrm{kg})$. In contrast, microdialysis studies report a $\sim 3$-fold elevation in striatal DA levels at the same dose (Loland et al., 2012). These discrepancies may be attributed to differences in analytical techniques. Traditionally, microdialysis has been used to measure basal DA levels due to its high chemical selectivity and sensitive detection limits (Watson et al., 2006), whereas FSCV is better suited for capturing rapid changes in DA levels, such as DA transients, based on fast temporal resolution and smaller probe size (Roberts et al., 2013). Due to recent technical improvements in FSCV, along with advances in data analysis using PCR, changes in basal DA levels are now beginning to be assessed with this technique (Keithley et al., 2009). However, discrepancies between FSCV and microdialysis in 
measuring basal DA levels are not well understood and as a result, the definitive determination of whether MOD acts on basal DA levels requires further study.

Modafinil Effects on Phasic Dopamine Signaling. Naturally occurring DA transients can be mimicked in amplitude and dynamics using electrical stimulation with judicious selection of stimulus parameters (Robinson et al., 2001). The stimulus parameters used here are reinforcing in the paradigm of intracranial self-stimulation (Garris et al., 1999; Cheer et al., 2005) and elicit DA signals whose amplitude falls within the range of these DA transients, albeit at the higher end (Robinson and Wightman, 2007). DAT-inhibiting psychomotor stimulants, such as cocaine and amphetamine, have also been shown to robustly increase the amplitude of DA signals evoked by similar stimulus parameters (Venton et al., 2006; Oleson et al., 2009; Ramsson et al., 2011; Covey et al., 2013; Avelar et al., 2013). This increase in the electrically evoked DA signal is thought to be relevant to drug action on phasic DA signaling, because both cocaine and amphetamine also robustly activate DA transients in awake, freely behaving animals (Stuber et al., 2005; Aragona et al., 2008; Daberkow et al., 2013). Whether MOD also elicits DA transients in awake, freely behaving animals as do cocaine and amphetamine remains to be determined. However, we also showed that MOD elicits DA transients in the presence of raclopride, similar to cocaine (Park et al., 2010), further suggesting that the activation of phasic DA signaling we observed for MOD in anesthetized animals, as indexed by electrically evoked phasic-like DA signals and DA transients measured in the presence of a DA D2 antagonist, is indicative of drug action in awake, freely behaving animals. 
Similar to other DAT-inhibiting psychomotor stimulants such as cocaine, amphetamine, and methylphenidate (Venton et al., 2006; Ramsson et al., 2011;

Chadchankar et al., 2012; Covey et al., 2013; Avelar et al., 2013; Daberkow et al., 2013), we show that MOD increases DA release and decreases DA uptake. Thus, our results are consistent with the notion that DAT-inhibiting psychomotor stimulants share a common action of altering both presynaptic mechanisms (Covey et al., 2014). Because the upward slope of the electrically evoked DA signal is determined by the balance of DA release and uptake (Wightman et al., 1988), both presynaptic mechanisms could in theory mediate the increase in amplitude of the electrically evoked phasic-like signaling elicited by DAT-inhibiting psychomotor stimulants. However, while indirect evidence suggests that the increase in DA release is more responsible for the increase in signal amplitude compared to the decrease in DA uptake (Venton et al., 2006; Avelar et al., 2013; Covey et al., 2013; Daberkow et al., 2013), this hypothesis has never been directly tested as we do here. Indeed, our results using path analysis suggest that MOD-induced increases in $[D A]_{\max }$ are best explained by the enhancement of DA release, not the inhibition of DA uptake. This result, if substantiated, may inform the regulation of DA transients by DATinhibiting psychomotor stimulants. For example, while it is thought that an increase in burst firing of DA neurons drives the increase in transient frequency (vide infra) and inhibited DA uptake drives the increase in transient duration, the mechanism of the increase in transient amplitude is debated (Covey et al., 2013). Assuming electrically evoked phasic-liked DA signals appropriately model DA transients, our results suggest that enhanced DA release, not inhibited DA uptake, is responsible for the increase in transient frequency with DAT-inhibiting psychomotor stimulants. However, caution is 
urged, because there are other kinetic models available for analyzing DA release and uptake from the electrically evoked DA signal (Walters et al., 2014; Harun et al., 2015) besides the diffusion-gap model that we employed, and these models should also be applied to address the relative contribution of DA release and DA uptake to [DA $]_{\max }$.

Our findings show that MOD, at the lowest dose tested (30 mg/kg), elicited DA transients in both the dorsal and ventral striatum. Interestingly, the frequency of DA transient elicited was similar to that for a high affinity DAT-inhibitor, nomifensine, under similar conditions (Venton and Wightman, 2007), which suggests that the MOD-induced activation of DA transients is robust. Because co-administration of a DA D2 antagonist is a confound, it is difficult to compare these rates of transient frequency activation with those observed with DAT-inhibiting psychomotor stimulants in awake, freely behaving animals. The ability of MOD to increase the frequency of DA transients in the dorsal and ventral striatum would appear to be due to activation of burst firing of DA neurons. Anesthetics blunt this burst firing (Kelland et al., 1990) and under these conditions, DATinhibiting psychomotor stimulants inhibit the firing rate of DA neurons (Shi et al., 2000; Shi et al., 2004). However, administration of a DA D2 antagonist relieves the blunting effects of anesthesia and reveals a drug-induced activation of burst firing of DA neurons similar to that observed in awake, freely behaving animals (Shi et al., 2000; Shi et al., 2004; Koulchitsky et al., 2012). We therefore hypothesize that MOD similarly increases burst firing of DA neurons in awake, freely behaving animal, although this hypothesis remains to be tested. Taken together, our results obtained in the urethane-anesthetized rat suggest the MOD mechanism of eliciting burst firing of DA neurons, which generates DA transients in the dorsal and ventral striatum, and increasing the amplitude and 
duration of these DA transients by the presynaptic actions of enhancing DA release and inhibiting DA uptake, respectively. Our results, furthermore, do not implicate an action of MOD on tonic DA signaling.

Addictive Nature of Psychomotor Stimulants. A long-held view in addiction research is that, despite diverse cellular actions, all drugs of abuse increase brain extracellular levels of DA, with a preferential action in the ventral compared to the dorsal striatum (Di and Imperato, 1988). More recent work has refined this view by hypothesizing that all drugs of abuse hyperactive phasic DA signaling (Cheer et al., 2004; Cheer et al., 2007; Daberkow et al., 2013; Vander Weele et al., 2014), leading to the hijacking of reward circuits and aberrant reward learning (Hyman et al., 2006). While cocaine and amphetamine conform to this general hypothesis (Venton and Wightman, 2007; Covey et al., 2013; Daberkow et al., 2013), other mechanisms have been considered to explain differences in abuse potential for DAT-inhibiting psychomotor stimulants including, affinity for DAT (Ritz et al., 1987), speed of drug action in the brain (Yorgason et al., 2011), and actions on DAT mimicking G protein-coupled receptors, as in the so-called "transceptor" (Schmitt et al., 2013). We also show here that in contrast to the addictive DAT-inhibiting psychomotor stimulants, cocaine and amphetamine, which elicit preferential increases in phasic DA signaling in the ventral compared to the dorsal striatum (Ritz et al., 1987; Wu et al., 2001a; Ramsson et al., 2011; Covey et al., 2013), MOD either preferentially increased electrically evoked phasic-like DA signals in the dorsal compared to the ventral striatum or shows no striatal sub-region preference for activating DA transients. Consistent with this effect, nomifensine, another DAT-inhibiting psychomotor stimulant with limited abuse potential (Tella et al., 1997), 
showed a similar preference for the dorsal striatum in increasing electrically evoked phasic-like DA signals (Wu et al., 2001a). Whether other DAT-inhibiting psychomotor stimulants with limited abuse potential show a similar preference for activating phasic DA signaling in the dorsal compared to the ventral striatum should be further pursued.

Clinical Implications of Modafinil. Phasic DA signaling is critical in reward seeking and learning (Schultz et al., 1997; Adamantidis et al., 2011), and reinforcement deficits in ADHD patients are thought to arise from alterations in phasic DA signaling (Tripp and Wickens, 2008). As MOD has been shown to remediate cognitive deficits in ADHD (Swanson et al., 2006) and enhance cognition in non-ADHD patients (Muller et al., 2013), it is interesting to speculate that MOD's ability to activate phasic DA signaling may contribute to its clinical efficacy. Additionally, phasic DA signaling has been linked to cocaine self-administration (Willuhn et al., 2014), while MOD reduces cocaine and methamphetamine administration in addicts (Anderson et al., 2009; Shearer et al., 2009). Long-access cocaine self-administration also diminishes phasic DA signaling in the striatum, but treatment with L-DOPA can restore phasic DA signaling and concomitantly, cocaine self-administration decreases (Willuhn et al., 2014). Thus, it is interesting to speculate that perhaps MOD's ability to activate phasic DA signaling may restore drugdepressed phasic DA signaling, similarly to L-DOPA, and ultimately aid in the treatment of drug addiction.

In addition to cognitive enhancement and drug addiction therapy, MOD is a wellestablished wake promoting agent. The mechanism of narcoleptic therapeutics is incompletely understood, and MOD's mechanism of treating narcolepsy is unknown. More recent evidence suggests a role for DA in sleep-wakefulness (Wisor et al., 2001; 
Dahan et al., 2007), in addition to the well-established roles of serotonin, norepinephrine, and acetylcholine (Pace-Schott and Hobson, 2002). Burst-firing of DA neurons also changes between wake and paradoxical sleep states (Dahan et al., 2007). As burst firing of DA neurons generates DA transients, it is interesting to speculate that MOD's ability to activate phasic DA signaling may be involved in promoting wakefulness.

Conclusion. Our results suggest that MOD's therapeutic efficacy may be due, at least in part, to its ability to activate phasic DA signaling. Further study in awake, freely behaving animals should be pursued to substantiate this hypothesis based on evidence described herein and collected in anesthetized animals. 


\section{REFERENCES}

Adamantidis AR, Tsai HC, Boutrel B, Zhang F, Stuber GD, Budygin EA, Tourino C, Bonci A, Deisseroth K, de LL (Optogenetic interrogation of dopaminergic modulation of the multiple phases of reward-seeking behavior. J Neurosci 31:10829-10835.2011).

Anderson AL, Li SH, Biswas K, McSherry F, Holmes T, Iturriaga E, Kahn R, Chiang N, Beresford T, Campbell J, Haning W, Mawhinney J, McCann M, Rawson R, Stock C, Weis D, Yu E, Elkashef AM (Modafinil for the treatment of methamphetamine dependence. Drug Alcohol Depend 120:135-141.2012).

Anderson AL, Reid MS, Li SH, Holmes T, Shemanski L, Slee A, Smith EV, Kahn R, Chiang N, Vocci F, Ciraulo D, Dackis C, Roache JD, Salloum IM, Somoza E, Urschel HC, III, Elkashef AM (Modafinil for the treatment of cocaine dependence. Drug Alcohol Depend 104:133-139.2009).

Aragona BJ, Cleaveland NA, Stuber GD, Day JJ, Carelli RM, Wightman RM (Preferential enhancement of dopamine transmission within the nucleus accumbens shell by cocaine is attributable to a direct increase in phasic dopamine release events. J Neurosci 28:8821-8831.2008).

Avelar AJ, Juliano SA, Garris PA (Amphetamine augments vesicular dopamine release in the dorsal and ventral striatum through different mechanisms. J Neurochem 125:373-385.2013).

Ballon JS, Feifel D (A systematic review of modafinil: Potential clinical uses and mechanisms of action. J Clin Psychiatry 67:554-566.2006).

Barch DM, Carter CS (Amphetamine improves cognitive function in medicated individuals with schizophrenia and in healthy volunteers. Schizophr Res 77:4358.2005).

Battleday RM, Brem AK (Modafinil for cognitive neuroenhancement in healthy nonsleep-deprived subjects: A systematic review. Eur Neuropsychopharmacol.2015).

Beracochea D, Cagnard B, Celerier A, le MJ, Peres M, Pierard C (First evidence of a delay-dependent working memory-enhancing effect of modafinil in mice. Neuroreport 12:375-378.2001).

Chadchankar H, Ihalainen J, Tanila H, Yavich L (Methylphenidate modifies overflow and presynaptic compartmentalization of dopamine via an alpha-synucleindependent mechanism. J Pharmacol Exp Ther 341:484-492.2012). 
Chadchankar H, Yavich L (Characterization of a 32mum diameter carbon fiber electrode for in vivo fast-scan cyclic voltammetry. J Neurosci Methods 211:218-226.2012).

Cheer JF, Heien ML, Garris PA, Carelli RM, Wightman RM (Simultaneous electrochemical and single-unit recordings in the nucleus accumbens reveal GABA-mediated responses: implications for intracranial self-stimulation. Proc Natl Acad Sci U S A 102:19150-19155.2005).

Cheer JF, Wassum KM, Heien ML, Phillips PE, Wightman RM (Cannabinoids enhance subsecond dopamine release in the nucleus accumbens of awake rats. J Neurosci 24:4393-4400.2004).

Cheer JF, Wassum KM, Sombers LA, Heien ML, Ariansen JL, Aragona BJ, Phillips PE, Wightman RM (Phasic dopamine release evoked by abused substances requires cannabinoid receptor activation. J Neurosci 27:791-795.2007).

Chemelli RM, Willie JT, Sinton CM, Elmquist JK, Scammell T, Lee C, Richardson JA, Williams SC, Xiong Y, Kisanuki Y, Fitch TE, Nakazato M, Hammer RE, Saper $\mathrm{CB}$, Yanagisawa M (Narcolepsy in orexin knockout mice: molecular genetics of sleep regulation. Cell 98:437-451.1999).

Covey DP, Juliano SA, Garris PA (Amphetamine elicits opposing actions on readily releasable and reserve pools for dopamine. PLoS One 8:e60763.2013).

Covey DP, Roitman MF, Garris PA (Illicit dopamine transients: reconciling actions of abused drugs. Trends Neurosci In Press.2014).

Czeisler CA, Walsh JK, Roth T, Hughes RJ, Wright KP, Kingsbury L, Arora S, Schwartz JR, Niebler GE, Dinges DF (Modafinil for excessive sleepiness associated with shift-work sleep disorder. N Engl J Med 353:476-486.2005).

Daberkow DP, Brown HD, Bunner KD, Kraniotis SA, Doellman MA, Ragozzino ME, Garris PA, Roitman MF (Amphetamine paradoxically augments exocytotic dopamine release and phasic dopamine signals. J Neurosci 33:452-463.2013).

Dahan L, Astier B, Vautrelle N, Urbain N, Kocsis B, Chouvet G (Prominent burst firing of dopaminergic neurons in the ventral tegmental area during paradoxical sleep. Neuropsychopharmacology 32:1232-1241.2007).

Day JJ, Roitman MF, Wightman RM, Carelli RM (Associative learning mediates dynamic shifts in dopamine signaling in the nucleus accumbens. Nat Neurosci 10:1020-1028.2007).

de Saint HZ, Orosco M, Rouch C, Blanc G, Nicolaidis S (Variations in extracellular monoamines in the prefrontal cortex and medial hypothalamus after modafinil administration: a microdialysis study in rats. Neuroreport 12:3533-3537.2001).

Deroche-Gamonet V, Darnaudery M, Bruins-Slot L, Piat F, Le MM, Piazza PV (Study of the addictive potential of modafinil in naive and cocaine-experienced rats. Psychopharmacology (Berl) 161:387-395.2002). 
Di CG, Imperato A (Drugs abused by humans preferentially increase synaptic dopamine concentrations in the mesolimbic system of freely moving rats. Proc Natl Acad Sci U S A 85:5274-5278.1988).

Edgar DM, Seidel WF (Modafinil induces wakefulness without intensifying motor activity or subsequent rebound hypersomnolence in the rat. J Pharmacol Exp Ther 283:757-769.1997).

Ferraro L, Antonelli T, O'Connor WT, Tanganelli S, Rambert F, Fuxe K (The antinarcoleptic drug modafinil increases glutamate release in thalamic areas and hippocampus. Neuroreport 8:2883-2887.1997a).

Ferraro L, Antonelli T, O'Connor WT, Tanganelli S, Rambert FA, Fuxe K (Modafinil: an antinarcoleptic drug with a different neurochemical profile to d-amphetamine and dopamine uptake blockers. Biol Psychiatry 42:1181-1183.1997b).

Garris PA, Kilpatrick M, Bunin MA, Michael D, Walker QD, Wightman RM (Dissociation of dopamine release in the nucleus accumbens from intracranial self-stimulation. Nature 398:67-69.1999).

Grace AA, Bunney BS (The control of firing pattern in nigral dopamine neurons: burst firing. J Neurosci 4:2877-2890.1984a).

Grace AA, Bunney BS (The control of firing pattern in nigral dopamine neurons: single spike firing. J Neurosci 4:2866-2876.1984b).

Harun R, Grassi CM, Munoz MJ, Torres GE, Wagner AK (Neurobiological model of stimulated dopamine neurotransmission to interpret fast-scan cyclic voltammetry data. Brain Res 1599:67-84.2015).

Heien ML, Johnson MA, Wightman RM (Resolving neurotransmitters detected by fastscan cyclic voltammetry. Anal Chem 76:5697-5704.2004).

Hermans A, Keithley RB, Kita JM, Sombers LA, Wightman RM (Dopamine detection with fast-scan cyclic voltammetry used with analog background subtraction. Anal Chem 80:4040-4048.2008).

Hyman SE, Malenka RC, Nestler EJ (Neural mechanisms of addiction: the role of reward-related learning and memory. Annu Rev Neurosci 29:565-598.2006).

Ishizuka T, Murakami M, Yamatodani A (Involvement of central histaminergic systems in modafinil-induced but not methylphenidate-induced increases in locomotor activity in rats. Eur J Pharmacol 578:209-215.2008).

Ishizuka T, Sakamoto Y, Sakurai T, Yamatodani A (Modafinil increases histamine release in the anterior hypothalamus of rats. Neurosci Lett 339:143-146.2003).

Keithley RB, Heien ML, Wightman RM (Multivariate concentration determination using principal component regression with residual analysis. Trends Analyt Chem 28:1127-1136.2009). 
Kelland MD, Chiodo LA, Freeman AS (Anesthetic influences on the basal activity and pharmacological responsiveness of nigrostriatal dopamine neurons. Synapse 6:207-209.1990).

Koulchitsky S, De BB, Quertemont E, Charlier C, Seutin V (Differential effects of cocaine on dopamine neuron firing in awake and anesthetized rats. Neuropsychopharmacology 37:1559-1571.2012).

Kuczenski R, Segal DS (Locomotor effects of acute and repeated threshold doses of amphetamine and methylphenidate: relative roles of dopamine and norepinephrine. J Pharmacol Exp Ther 296:876-883.2001).

Kuczenski R, Segal DS, Aizenstein ML (Amphetamine, cocaine, and fencamfamine: relationship between locomotor and stereotypy response profiles and caudate and accumbens dopamine dynamics. J Neurosci 11:2703-2712.1991).

Kumar R (Approved and investigational uses of modafinil : an evidence-based review. Drugs 68:1803-1839.2008).

Kume-Kick J, Rice ME (Dependence of dopamine calibration factors on media Ca2+ and $\mathrm{Mg} 2+$ at carbon-fiber microelectrodes used with fast-scan cyclic voltammetry. $\mathrm{J}$ Neurosci Methods 84:55-62.1998).

Loland CJ, Mereu M, Okunola OM, Cao J, Prisinzano TE, Mazier S, Kopajtic T, Shi L, Katz JL, Tanda G, Newman AH (R-modafinil (armodafinil): a unique dopamine uptake inhibitor and potential medication for psychostimulant abuse. Biol Psychiatry 72:405-413.2012).

Madras BK, Xie Z, Lin Z, Jassen A, Panas H, Lynch L, Johnson R, Livni E, Spencer TJ, Bonab AA, Miller GM, Fischman AJ (Modafinil occupies dopamine and norepinephrine transporters in vivo and modulates the transporters and trace amine activity in vitro. J Pharmacol Exp Ther 319:561-569.2006).

Michael D, Travis ER, Wightman RM (Color images for fast-scan CV measurements in biological systems. Anal Chem 70:586A-592A.1998).

Mignot E, Nishino S, Guilleminault C, Dement WC (Modafinil binds to the dopamine uptake carrier site with low affinity. Sleep 17:436-437.1994).

Muller U, Rowe JB, Rittman T, Lewis C, Robbins TW, Sahakian BJ (Effects of modafinil on non-verbal cognition, task enjoyment and creative thinking in healthy volunteers. Neuropharmacology 64:490-495.2013).

Oleson EB, Talluri S, Childers SR, Smith JE, Roberts DC, Bonin KD, Budygin EA (Dopamine uptake changes associated with cocaine self-administration. Neuropsychopharmacology 34:1174-1184.2009).

Pace-Schott EF, Hobson JA (The neurobiology of sleep: genetics, cellular physiology and subcortical networks. Nat Rev Neurosci 3:591-605.2002). 
Pack AI, Black JE, Schwartz JR, Matheson JK (Modafinil as adjunct therapy for daytime sleepiness in obstructive sleep apnea. Am J Respir Crit Care Med 164:16751681.2001).

Park J, Aragona BJ, Kile BM, Carelli RM, Wightman RM (In vivo voltammetric monitoring of catecholamine release in subterritories of the nucleus accumbens shell. Neuroscience 169:132-142.2010).

Paxinos G, Watson C (1986) The rat brain in stereotaxic coordinates. New York: Academic Press.

Phillips PE, Robinson DL, Stuber GD, Carelli RM, Wightman RM (Real-time measurements of phasic changes in extracellular dopamine concentration in freely moving rats by fast-scan cyclic voltammetry. Methods Mol Med 79:443464.2003a).

Phillips PE, Stuber GD, Heien ML, Wightman RM, Carelli RM (Subsecond dopamine release promotes cocaine seeking. Nature 422:614-618.2003b).

Ramsson ES, Howard CD, Covey DP, Garris PA (High doses of amphetamine augment, rather than disrupt, exocytotic dopamine release in the dorsal and ventral striatum of the anesthetized rat. J Neurochem 119:1162-1172.2011).

Repantis D, Schlattmann P, Laisney O, Heuser I (Modafinil and methylphenidate for neuroenhancement in healthy individuals: A systematic review. Pharmacol Res 62:187-206.2010).

Ritz MC, Lamb RJ, Goldberg SR, Kuhar MJ (Cocaine receptors on dopamine transporters are related to self- administration of cocaine. Science 237:12191223.1987).

Roberts JG, Lugo-Morales LZ, Loziuk PL, Sombers LA (Real-time chemical measurements of dopamine release in the brain. Methods Mol Biol 964:275294.2013).

Robinson DL, Phillips PE, Budygin EA, Trafton BJ, Garris PA, Wightman RM (Subsecond changes in accumbal dopamine during sexual behavior in male rats. Neuroreport 12:2549-2552.2001).

Robinson DL, Wightman RM (2007) Rapid dopamine release in freely moving rats. In: Electrochemical Methods for Neuroscience (Michael AC, Borland LM, eds), pp 17-34 Boca Raton: CRC Press.

Schmitt KC, Rothman RB, Reith ME (Nonclassical pharmacology of the dopamine transporter: atypical inhibitors, allosteric modulators, and partial substrates. J Pharmacol Exp Ther 346:2-10.2013).

Schultz W, Dayan P, Montague PR (A neural substrate of prediction and reward. Science 275:1593-1599.1997). 
Shearer J, Darke S, Rodgers C, Slade T, van B, I, Lewis J, Brady D, McKetin R, Mattick RP, Wodak A (A double-blind, placebo-controlled trial of modafinil (200 mg/day) for methamphetamine dependence. Addiction 104:224-233.2009).

Shi WX, Pun CL, Zhang XX, Jones MD, Bunney BS (Dual effects of D-amphetamine on dopamine neurons mediated by dopamine and nondopamine receptors. J Neurosci 20:3504-3511.2000).

Shi WX, Pun CL, Zhou Y (Psychostimulants induce low-frequency oscillations in the firing activity of dopamine neurons. Neuropsychopharmacology 29:21602167.2004).

Sombers LA, Beyene M, Carelli RM, Wightman RM (Synaptic overflow of dopamine in the nucleus accumbens arises from neuronal activity in the ventral tegmental area. J Neurosci 29:1735-1742.2009).

Stuber GD, Roitman MF, Phillips PE, Carelli RM, Wightman RM (Rapid dopamine signaling in the nucleus accumbens during contingent and noncontingent cocaine administration. Neuropsychopharmacology 30:853-863.2005).

Swanson JM, Greenhill LL, Lopez FA, Sedillo A, Earl CQ, Jiang JG, Biederman J (Modafinil film-coated tablets in children and adolescents with attentiondeficit/hyperactivity disorder: results of a randomized, double-blind, placebocontrolled, fixed-dose study followed by abrupt discontinuation. J Clin Psychiatry 67:137-147.2006).

Tanganelli S, Fuxe K, Ferraro L, Janson AM, Bianchi C (Inhibitory effects of the psychoactive drug modafinil on gamma-aminobutyric acid outflow from the cerebral cortex of the awake freely moving guinea-pig. Possible involvement of 5hydroxytryptamine mechanisms. Naunyn Schmiedebergs Arch Pharmacol 345:461-465.1992).

Tella SR, Ladenheim B, Cadet JL (Differential regulation of dopamine transporter after chronic self-administration of bupropion and nomifensine. J Pharmacol Exp Ther 281:508-513.1997).

Tripp G, Wickens JR (Research review: dopamine transfer deficit: a neurobiological theory of altered reinforcement mechanisms in ADHD. J Child Psychol Psychiatry.2008).

Vander Weele CM, Porter-Stransky KA, Mabrouk OS, Lovic V, Singer BF, Kennedy RT, Aragona BJ (Rapid dopamine transmission within the nucleus accumbens: dramatic difference between morphine and oxycodone delivery. Eur J Neurosci 40:3041-3054.2014).

Venton BJ, Seipel AT, Phillips PE, Wetsel WC, Gitler D, Greengard P, Augustine GJ, Wightman RM (Cocaine increases dopamine release by mobilization of a synapsin-dependent reserve pool. J Neurosci 26:3206-3209.2006).

Venton BJ, Wightman RM (Pharmacologically induced, subsecond dopamine transients in the caudate-putamen of the anesthetized rat. Synapse 61:37-39.2007). 
Walters SH, Taylor IM, Shu Z, Michael AC (A novel restricted diffusion model of evoked dopamine. ACS Chem Neurosci 5:776-783.2014).

Ward CP, Harsh JR, York KM, Stewart KL, McCoy JG (Modafinil facilitates performance on a delayed nonmatching to position swim task in rats. Pharmacol Biochem Behav 78:735-741.2004).

Watson CJ, Venton BJ, Kennedy RT (In vivo measurements of neurotransmitters by microdialysis sampling. Anal Chem 78:1391-1399.2006).

Wightman RM, Amatore C, Engstrom RC, Hale PD, Kristensen EW, Kuhr WG, May LJ (Real-time characterization of dopamine overflow and uptake in the rat striatum. Neuroscience 25:513-523.1988).

Wightman RM, Kuhr WG, Ewing AG (Voltammetric detection of dopamine release in the rat corpus striatum. Ann N Y Acad Sci 473:92-105.1986).

Willuhn I, Burgeno LM, Groblewski PA, Phillips PE (Excessive cocaine use results from decreased phasic dopamine signaling in the striatum. Nat Neurosci 17:704709.2014).

Wise MS, Arand DL, Auger RR, Brooks SN, Watson NF (Treatment of narcolepsy and other hypersomnias of central origin. Sleep 30:1712-1727.2007).

Wisor JP, Nishino S, Sora I, Uhl GH, Mignot E, Edgar DM (Dopaminergic role in stimulant-induced wakefulness. J Neurosci 21:1787-1794.2001).

Wu Q, Reith ME, Kuhar MJ, Carroll FI, Garris PA (Preferential increases in nucleus accumbens dopamine after systemic cocaine administration are caused by unique characteristics of dopamine neurotransmission. J Neurosci 21:6338-6347.2001a).

Wu Q, Reith ME, Wightman RM, Kawagoe KT, Garris PA (Determination of release and uptake parameters from electrically evoked dopamine dynamics measured by real-time voltammetry. J Neurosci Methods 112:119-133.2001b).

Yorgason JT, Jones SR, Espana RA (Low and high affinity dopamine transporter inhibitors block dopamine uptake within $5 \mathrm{sec}$ of intravenous injection. Neuroscience 182:125-132.2011).

Zolkowska D, Jain R, Rothman RB, Partilla JS, Roth BL, Setola V, Prisinzano TE, Baumann $\mathrm{MH}$ (Evidence for the involvement of dopamine transporters in behavioral stimulant effects of modafinil. J Pharmacol Exp Ther 329:738746.2009). 


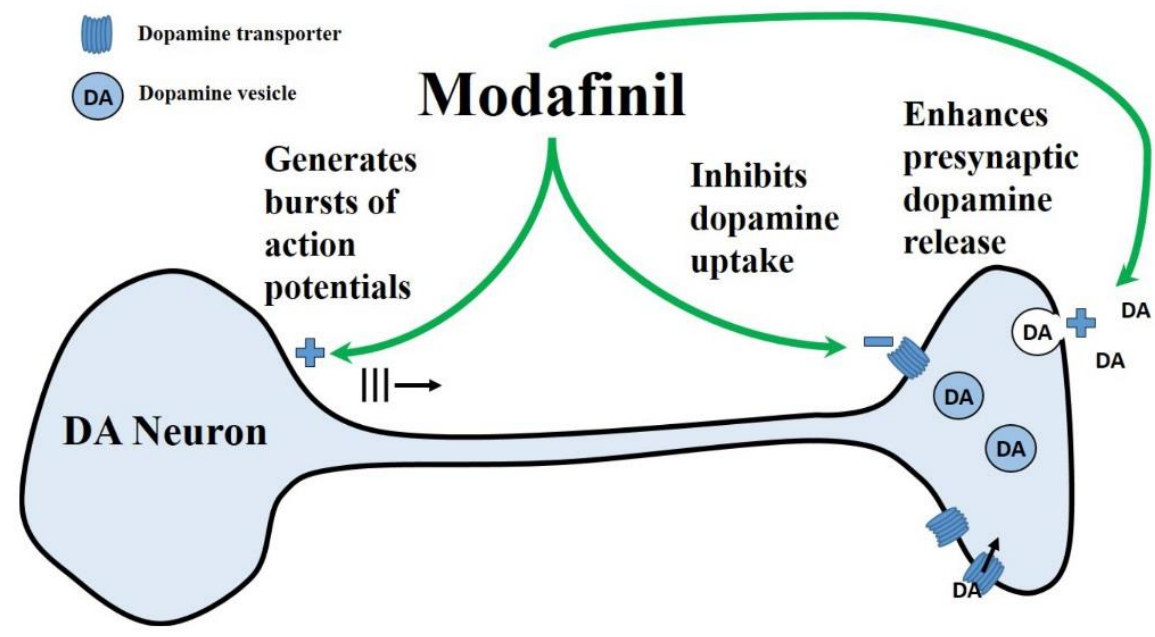

Pre-drug

Post-Modafinil
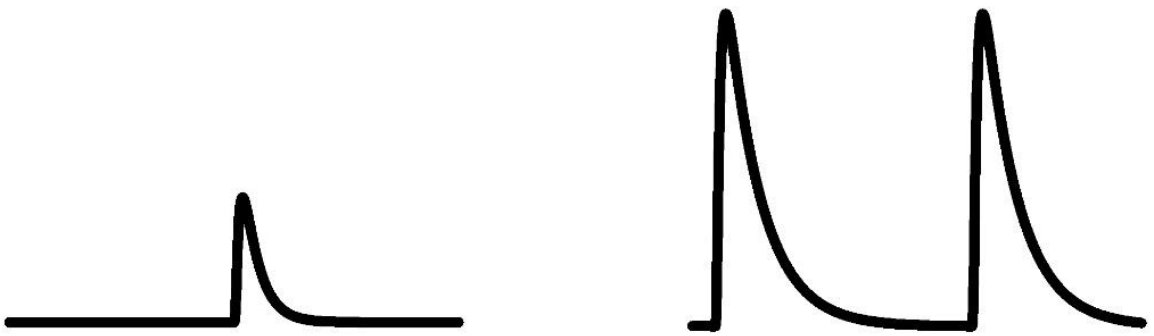

Figure 1. Schematic of modafinil effects on dopamine signaling. MOD generated DA transients in DA neuron terminal fields by activating burst firing at the level of the cell body. Furthermore, MOD enhanced phasic DA signaling at presynaptic levels by inhibiting DA uptake and enhancing DA release (top). MOD effects on phasic DA signaling results in increased frequency and enhanced amplitude of DA transients (bottom). 

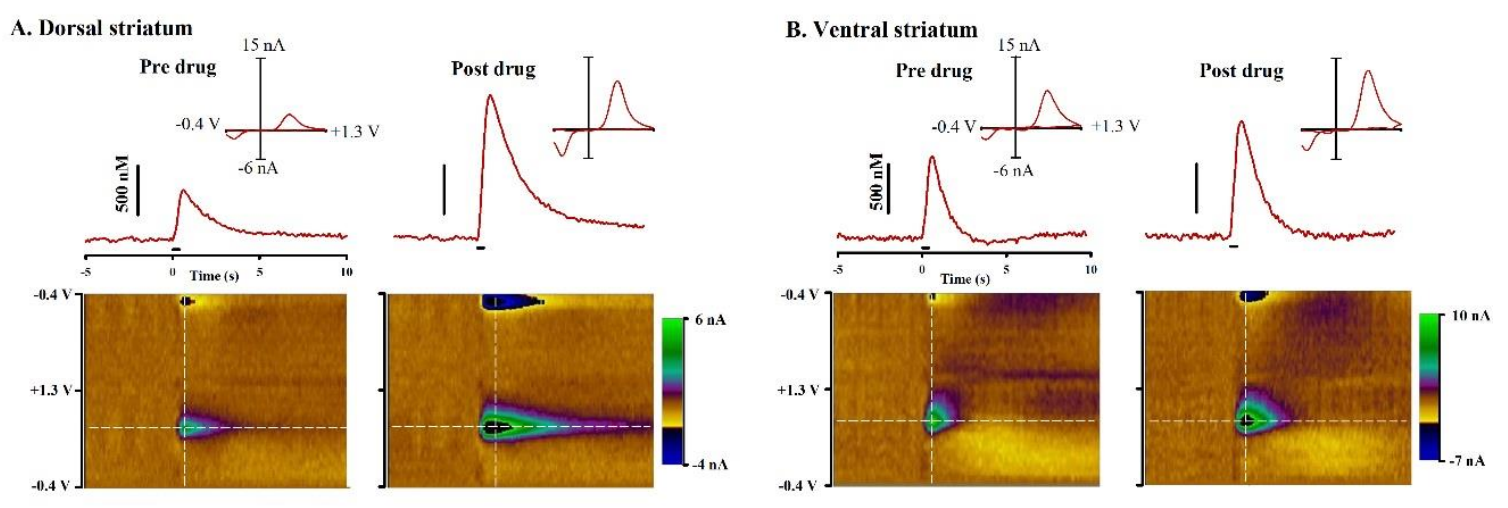

Figure 2. Representative effects of modafinil on electrically evoked phasic-like dopamine signals in the dorsal and ventral striatum. MOD (100 mg/kg i.p.) effects on electrically evoked phasic-like DA signals in the (A) dorsal and (B) ventral striatum measured by FSCV. (Top) Evoked DA signals elicited by electrical stimulation (demarcated by black line at time $0 \mathrm{~s}$ ) pre-drug (left) and 60 minutes post-MOD (right) administration. INSET. Individual background subtracted cyclic voltammogram taken from the peak signal amplitude (white vertical line) identifies the analyte as DA. (Bottom) Pseudo-color plot serially displaying all background-subtracted cyclic voltammograms (x-axis: time; y-axis: applied potential; z-axis: current). White horizontal line identifies the DA peak oxidation potential where the evoked DA trace was collected. 
A. Dorsal striatum

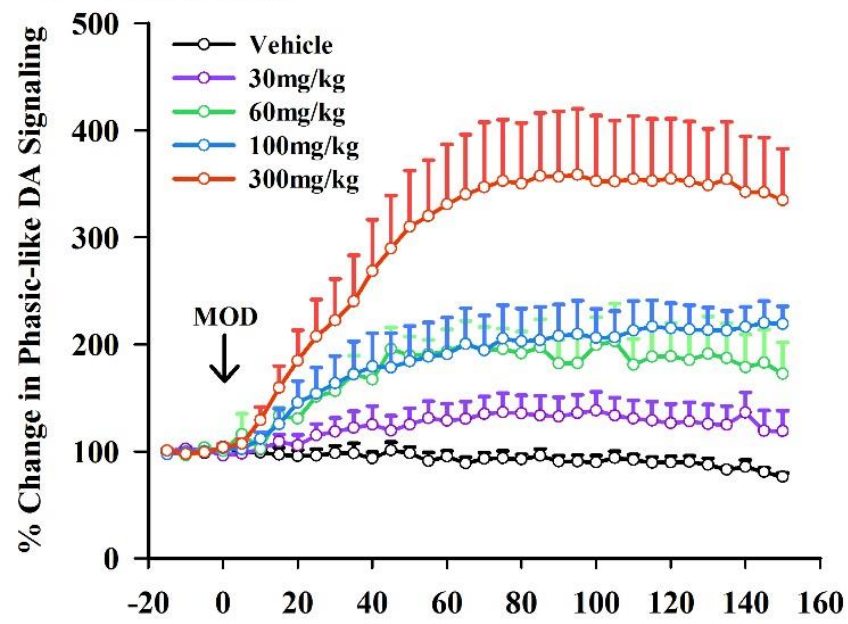

B. Ventral striatum

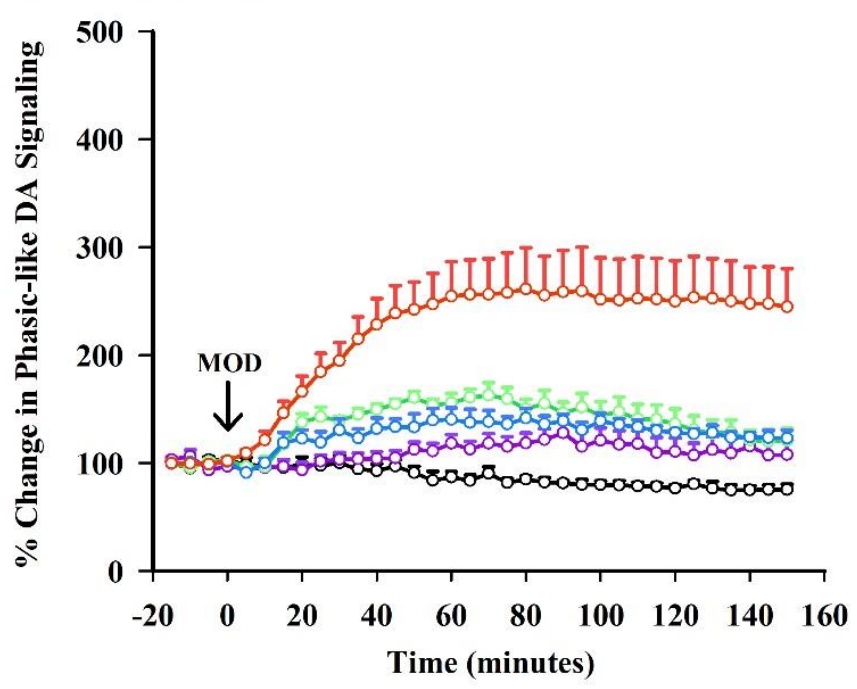

Figure 3. Average time courses of modafinil effects on $[\mathrm{DA}]_{\max }$ in the dorsal and ventral striatum. MOD elicits time- and dose-dependent effects on the maximal concentration of the electrically evoked phasic-like DA signal amplitude ([DA $]_{\max }$ ) in the dorsal (A) and ventral (B) striatum. Data are expressed as a percent of pre-drug and are the mean \pm SEM. Arrow demarcates MOD administration at time 0 min. Data were analyzed for significance using three-way repeated measures ANOVA $(n=4-7)$. 


\section{A. Dorsal Striatum}

$100 \mathrm{mg} / \mathrm{kg}$
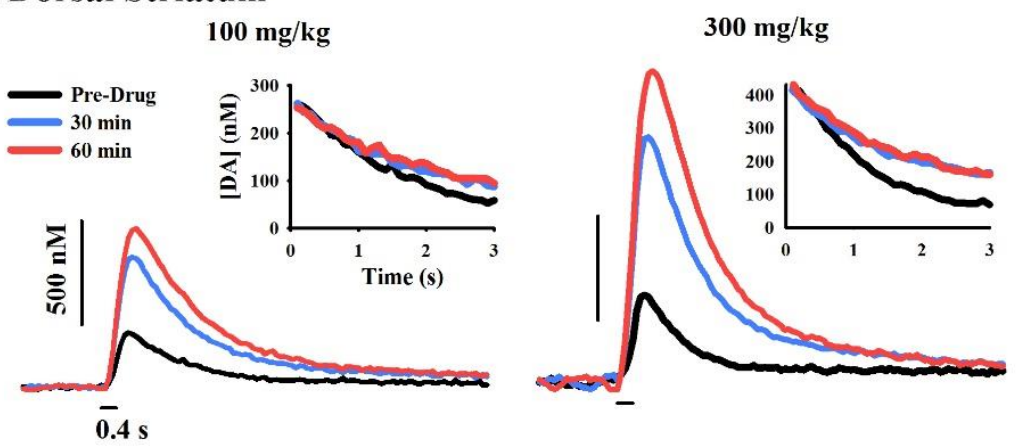

\section{B. Ventral Striatum}
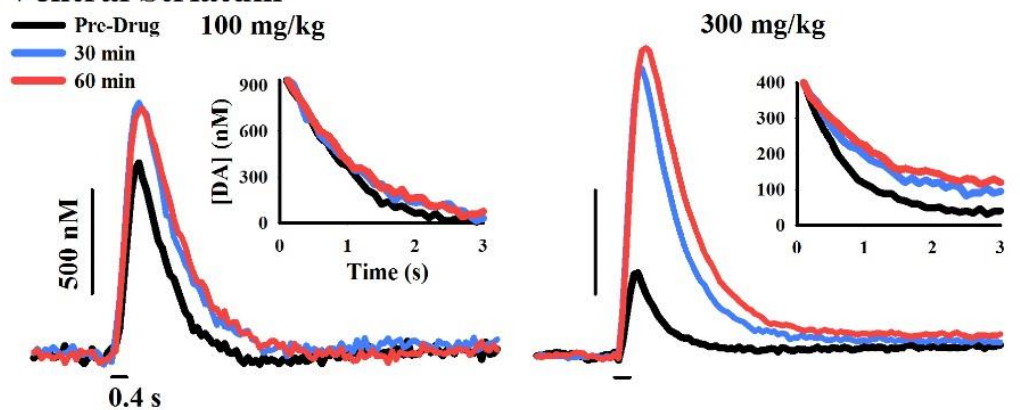

Figure 4. Qualitative analysis of dopamine uptake on electrically evoked phasic-like dopamine signals. Representative time- and dose-dependent effects of MOD on extracellular clearance of electrically evoked DA in the (A) dorsal and (B) ventral striatum. FSCV traces of electrically evoked DA signals (stimulus demarcated by short black line) are shown for $100 \mathrm{mg} / \mathrm{kg}$ MOD (left) and $300 \mathrm{mg} / \mathrm{kg}$ MOD (right) at select time points. INSET. Pre- and post-drug clearance curves are overlaid beginning at the same dopamine concentration and illustrate DA uptake inhibition. 
A. Dorsal Striatum

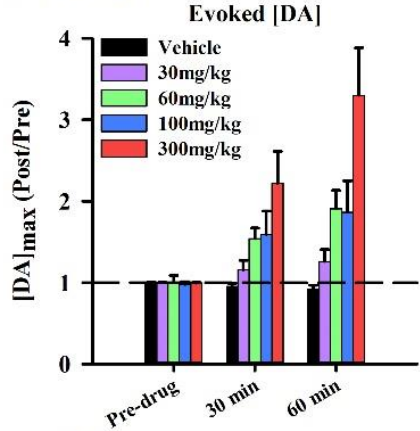

B. Ventral Striatum

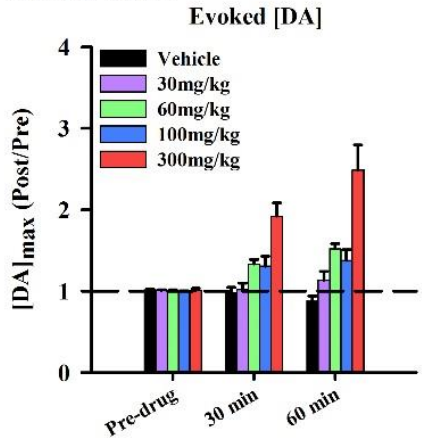

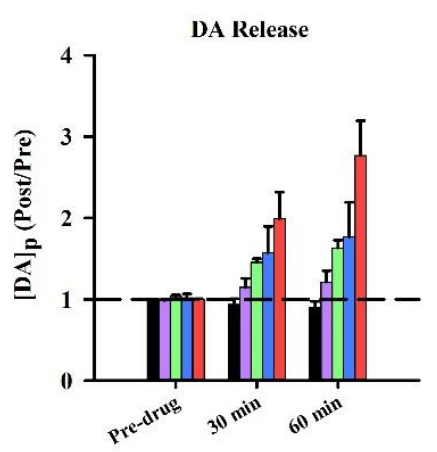

DA Release

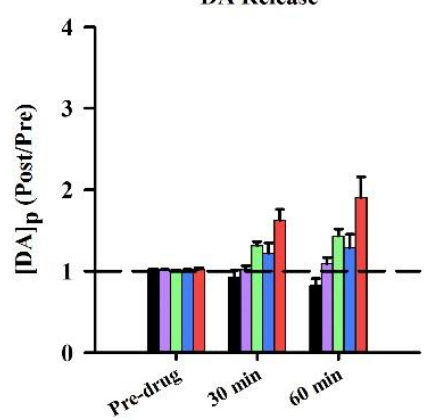

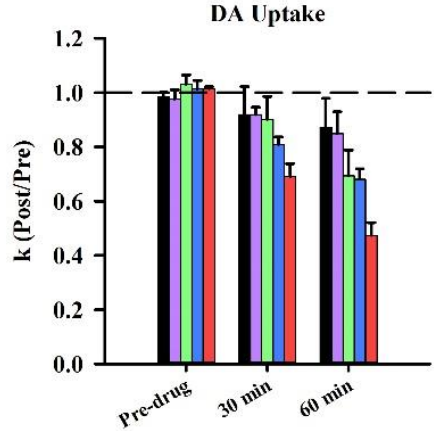

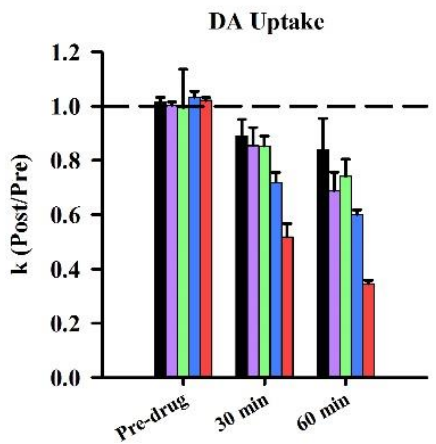

Figure 5. Effects of modafinil on $[\mathrm{DA}]_{\max }$, dopamine release, and dopamine uptake.

Increases in the maximal concentration of the electrically evoked phasic-like DA signal $\left([\mathrm{DA}]_{\max }\right)($ left) are associated with an increase in DA release (middle) and a decrease in DA uptake or k (right) in the dorsal (A) and ventral (B) striatum. Data are expressed as a percentage of pre-drug values and are the mean \pm SEM. Data were analyzed for significance using three-way repeated measures ANOVA $(n=4-7)$. 


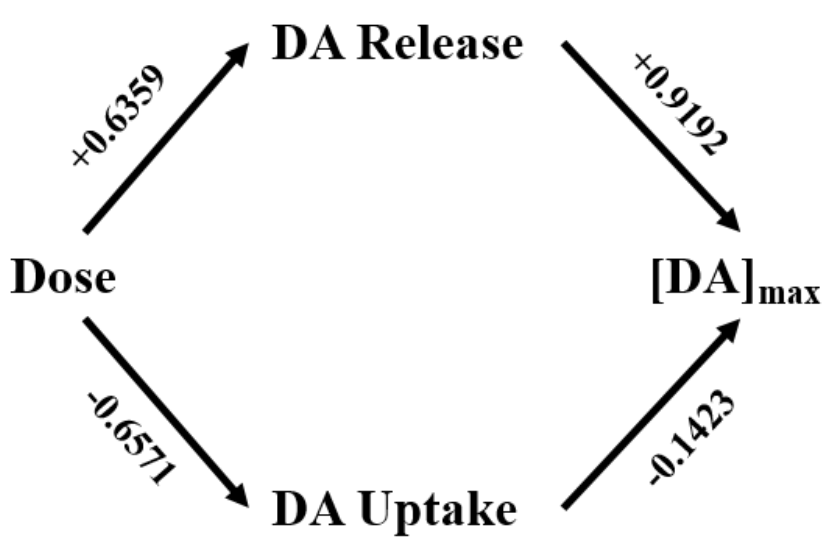

Figure 6. Path analysis of dose-dependent effects of modafinil on $[\mathrm{DA}]_{\max }$. Path analysis model demonstrating the direct relationships between dose, DA release, DA uptake and $[\mathrm{DA}]_{\max }$. Values given above each arrow are path coefficients describing each direct effect. 

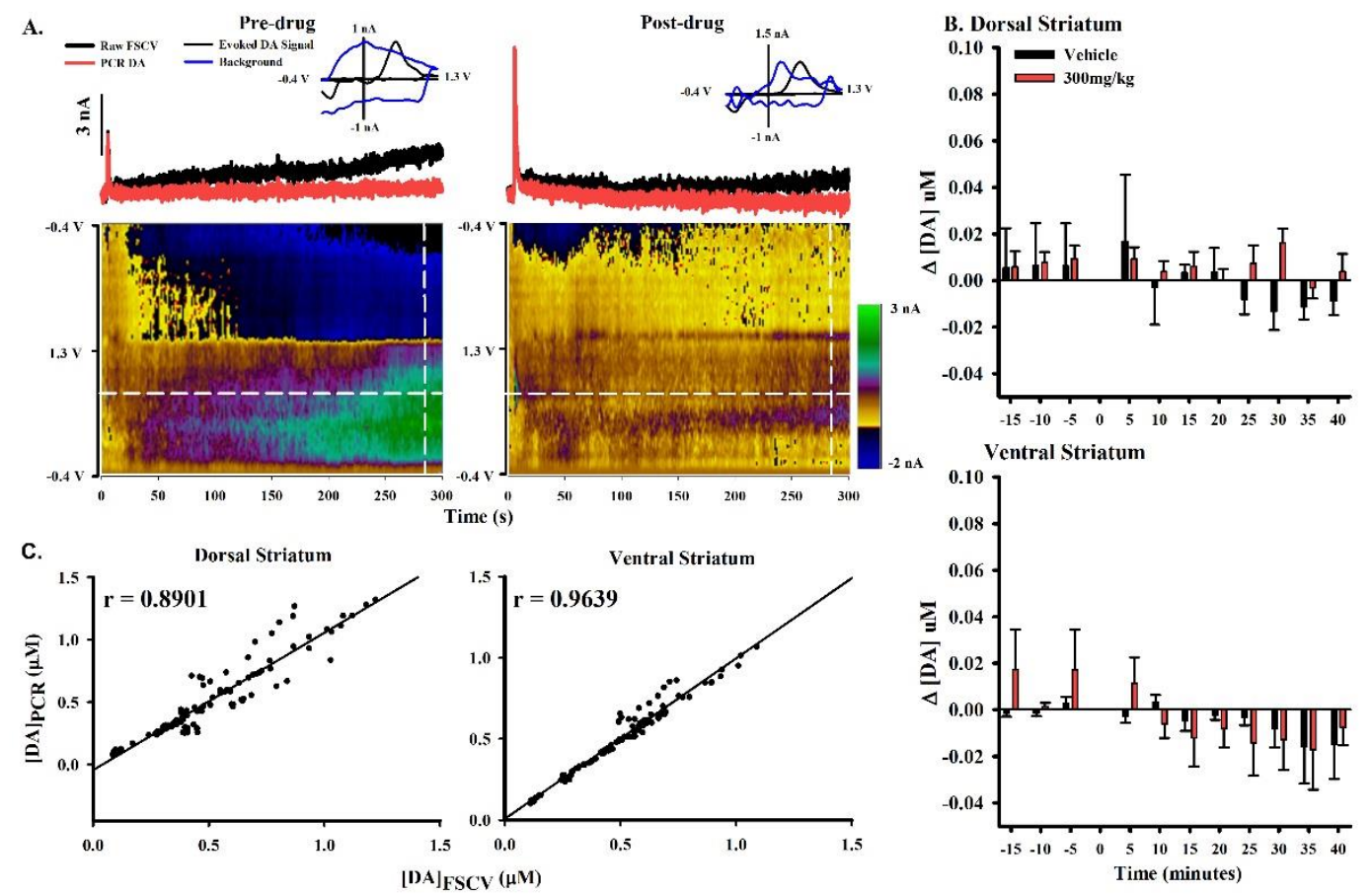

Figure 7. Effects of modafinil on non-electrically evoked dopamine signals. MOD

effects on changes in basal DA levels in the dorsal and ventral striatum. (A) The red line displays PCR resolved DA from the black FSCV trace (taken at the white horizontal line) for pre-drug and 60 minutes post-drug (300 mg/kg i.p.). A pseudo-color plot beneath displays all background subtracted cyclic voltammograms. INSET. Representative voltammogram (blue) collected at $285 \mathrm{~s}$ (white vertical line) overlaid with a voltammogram taken at peak electrically evoked signal (black). (B) PCR reveals no significant effect of MOD on baseline DA levels in the dorsal (top) and ventral (bottom) striatum. Data were analyzed for significance using three-way repeated measures ANOVA $(n=4)$. (C) Verification of PCR selectivity for the DA component in FSCV recordings. There was a strong correlation between $[\mathrm{DA}]_{\max }$ measured with FSCV ([DA $\left.]_{\mathrm{FSCV}}\right)$ and PCR ([DA $\left.]_{\mathrm{PCR}}\right)$ in both the dorsal (left) and ventral (right) striatum. 
A.
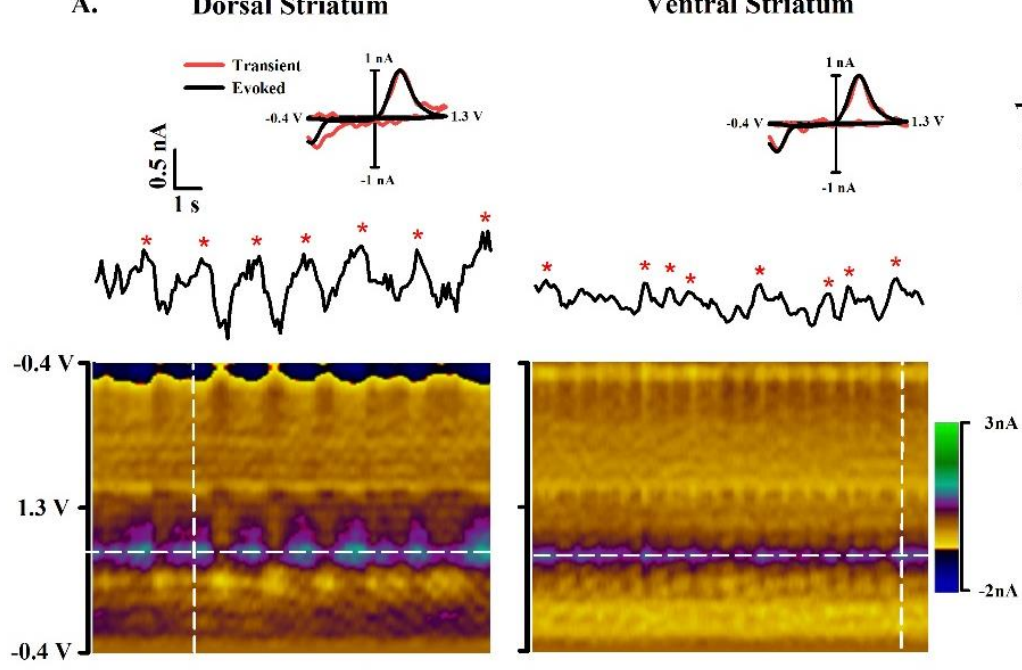

Figure 8. Modafinil effects on dopamine transients. DA transients are elicited in both the dorsal and ventral striatum by co-administration of MOD (30 mg/kg, i.p.) and raclopride ( $2 \mathrm{mg} / \mathrm{kg}$, i.p.). (A) Representative recording of DA transients in the dorsal (left) and ventral (right) striatum. A pseudo-color plot underneath serially displays all backgroundsubtracted cyclic voltammograms. Transients (denoted by red asterisks) are displayed in the FSCV current trace collected at the peak oxidative potential of DA (white horizontal line). INSET. Normalized background subtracted cyclic voltammograms taken from the electrically-evoked response (black line) and a DA transient (red line) collected at the white vertical line in the pseudo-color plot. (B) Average transient frequency per 5 minute epoch for pre- and post-drug administration expressed as mean \pm SEM. Data were analyzed for significance using two repeated measures ANOVA (dorsal, $n=6$; ventral $n$ =5). 
CHAPTER II

ATOMOXETINE ALTERS PHASIC DOPAMINE SIGNALING IN THE NUCLEUS

ACCUMBENS OF THE RAT: A PRELIMINARY STUDY 


\section{ABSTRACT}

Atomoxetine (ATX), brand name Strattera ${ }^{\circledR}$, has been approved for the treatment of attention deficit hyperactivity disorder (ADHD) in children, adolescents, and adults. By selectively targeting norepinephrine neurons, its underlying mechanism differs from that of the primary drugs used to treat ADHD, Adderall® and Ritalin®. Altered reinforcement learning is a symptom of ADHD that is proposed to be mediated by alterations in phasic dopamine (DA) signaling. During this mode of neural communication, burst firing of DA neurons generate rapid changes in extracellular DA concentrations in DA terminal fields termed DA transients. Although Adderall@ and Ritalin ${ }^{\circledR}$ are thought to act on phasic DA signaling, whether ATX shares this pharmacologic property is not known. ATX's effect on phasic DA signaling was investigated with fast-scan cyclic voltammetry at a carbon fiber microelectrode targeting the nucleus accumbens core. Three types of phasic DA signals were assessed: (1) electrically evoked phasic-like DA signals, which resemble naturally occurring DA transients; (2) spontaneously occurring DA transients, which are not ostensibly linked to external stimuli; (3) DA transients elicited by unexpected food delivery, which is considered a primary reward. Additionally, effects of ATX on the presynaptic mechanisms of DA release and DA uptake, determined from the electrically evoked signals, and ATX effects on food-pellet consumption were also assessed. Our preliminary results suggest that ATX reduces electrically evoked phasic-like DA signals, food-pellet consumption, and Food-evoked DA transients. Taken together, we propose that alteration of phasic DA signaling may contribute to the mechanism of ATX action. 


\section{Introduction}

Attention deficit hyperactivity disorder (ADHD) is a debilitating neurodevelopmental disorder, which affects approximately $6.5 \%$ of the world population (Polanczyk et al., 2014). Its two cardinal symptoms, inattention and hyperactivity-impulsivity, ultimately lead to poor success in academic and vocational pursuits (American Psychiatric Association, 2013). Current therapeutic medications for treating ADHD include two major classes of drugs: stimulants, amphetamine (AMPH; Adderall@) and methylphenidate (MPH; Ritalin $®)$, and the non-stimulant, atomoxetine (ATX; Strattera ${ }^{\circledR)}$. As compared to the commonly prescribed stimulant therapeutics, ATX possesses limited abuse potential (Tidey and Bergman, 1998; Jasinski et al., 2008), lacks locomotor activation (Tzavara et al., 2006), and is efficacious in treating comorbid conditions associated with ADHD, including depression and anxiety (Kratochvil et al., 2005). However, stimulant therapeutics provide immediate onset of action as opposed to ATX, which can take 3-4 weeks before achieving optimal therapeutic efficacy (Newcorn et al., 2008). ATX's mechanism of therapeutic efficacy remains incompletely understood, but because of its efficacy for the treatment of ADHD with comorbid depression and anxiety, along with its limited negative side-effects such as limited abuse potential, an understanding of its mechanism is critical for future drug development.

ADHD patients exhibit deficits in executive function, including planning, working memory, attention, and inhibition of inappropriate behaviors (American Psychiatric Association, 2013). Executive function is associated with the prefrontal cortex (PFC) (Alvarez and Emory, 2006), and ADHD patients are found to have altered PFC anatomy and function (Rubia et al., 2005; Booth et al., 2005). In addition, ADHD 
patients exhibit associative learning deficits, including atypical responses to reinforcement whereby patients choose small, instantaneous rewards rather than larger, delayed rewards (Sonuga-Barke, 2003; Antrop et al., 2006). Associative learning is linked to striatal function (Schultz, 1997; Day et al., 2007), and ADHD patients also exhibit anatomic and functional alterations in this region (Scheres et al., 2007). Altogether, symptoms in ADHD patients appear to be linked to abnormalities in both the PFC and striatum and befittingly, conceptual models of ADHD focus on neural alterations in these regions and their associated behaviors.

Current medications are thought to remediate symptoms of ADHD by ameliorating neurochemical alterations in the PFC. Studies in rats show that AMPH, MPH, and ATX enhance dopamine (DA) and norepinephrine (NE) levels in the PFC (Kuczenski and Segal, 2001; Bymaster et al., 2002; Kuczenski and Segal, 2002; Berridge and Stalnaker, 2002) and ameliorate symptoms of ADHD in humans (James et al., 2001; Correia Filho et al., 2005; Ince et al., 2015). These findings have contributed to the development of the inverted-U model of ADHD (Fig. 9). This model proposes that in the PFC optimal function is dependent on optimal catecholamine release, and either too low or too high levels of catecholamine release results in decreased PFC function (Arnsten and Pliszka, 2011). Furthermore, ADHD patients are suggested to have lower levels of catecholamine release, resulting in reduced PFC function and consequently, symptoms of ADHD. Medications for ADHD are thought to enhance levels of catecholamine release to more optimal levels, thereby enhancing PFC function and remediating symptoms of ADHD. 
The inverted-U model of ADHD addresses many of the executive functions altered in ADHD patients, but does not address alterations of associative learning. Thus, alternative models of ADHD have emerged that focus on alterations in associative learning (e.g., reinforcement learning) in the striatum. In particular, the dopamine transfer deficit (DTD) theory (Fig. 10) proposes that phasic DA signaling in DA neurons projecting from the midbrain to the striatum is altered in ADHD patients, which results in reinforcement learning deficits (Tripp and Wickens, 2008). Phasic DA signaling is critical for associative learning (Schultz et al., 1997) and is activated by primary rewards (e.g., food) (Brown et al., 2011a) and reward-predictive cues (Day et al., 2007). During normal reinforcement learning, phasic DA signaling is initially activated during reward delivery. During acquisition of learning, phasic DA signals begin to be activated during presentation of both the reward-predictive cue and the reward. Finally, later in learning, phasic DA signaling is exclusively activated during presentation of reward-predicting cues rather than reward delivery. The DTD theory hypothesizes that in ADHD patients, the transfer of phasic DA signaling to the cue is incomplete, resulting in reinforcement learning deficits. Furthermore, the theory proposes that ADHD medications ameliorate alterations in reinforcement learning by enhancing the magnitude of phasic DA signaling in the striatum elicited by the cue. However, this hypothesis has not yet been directly investigated to our knowledge.

Indeed it has been shown that drugs such as AMPH activate phasic DA signaling and this activation occurs through effects at the presynaptic level in the striatum (Avelar et al., 2013) as well as via afferent activation of DA neurons in the midbrain (Darracq et al., 1998; Shi et al., 2000; Shi et al., 2004). Phasic DA signaling is characterized by high 
frequency bursts of action potential firing (i.e., burst firing) (Grace and Bunney, 1984), resulting in sub-second increases in DA concentration in DA terminal fields termed DA transients. AMPH, a potent dopamine transporter (DAT)-inhibitor, also activates phasic DA signaling at presynaptic terminals by inhibiting DA uptake and enhancing DA release (Daberkow et al., 2013; Avelar et al., 2013). The resulting activation in phasic DA signaling leads to enhanced frequency, amplitude and duration of DA transients. In addition, AMPH is a potent norepinephrine transporter (NET)-inhibitor as well and enhances NE levels in the PFC (Berridge and Stalnaker, 2002), which has been shown to indirectly activate DA neuron burst firing via glutamate afferents to the midbrain (Fig. 11) (Darracq et al., 1998; Shi et al., 2000; Shi et al., 2004). Not unexpectedly then, selective NET-inhibitors enhance burst firing of DA neurons (Shi et al., 2000; Shi et al., 2004); however, their effects may also be mediated directly by activation of NE afferents to the midbrain DA neurons (Fig. 3). Similarly, ATX, a selective NET-inhibitor may be mediating its effects on phasic DA signaling via these mechanisms. However, due to the absence of direct actions on DA terminals, its actions on the frequency, duration, and amplitude of DA transients should be different than those of AMPH.

In the present study we sought it identify ATX's effect on phasic DA signaling in the freely behaving rat. Using fast-scan cyclic voltammetry (FSCV) at a carbon fiber microelectrode (CFM) targeting the nucleus accumbens core (NAc), a region that is activated during associative learning (Day et al., 2007), we examined the effects of ATX on phasic DA signaling during unexpected food delivery (UFD). Specifically, we investigated ATX effects on electrically evoked phasic-like DA transients, spontaneously occurring DA transients, and DA transients associated with UFD. Furthermore, we also 
investigated ATX effects on the presynaptic mechanisms of DA release and uptake and food-pellet consumption. 


\section{Methods and Materials}

Animals. Animal care was in accordance with NIH guidelines and approved by the Institutional Animal Care and Use Committee (IACUC) at Illinois State University. Male Sprague-Dawley rats (275-375 g) purchased from Harlan (Indianapolis, IN, USA) were housed in a temperature controlled vivarium on a diurnal light cycle (12h light/dark). Prior to training and during recovery, animals were provided food and water ad libitum. During magazine training and testing, animals were food restricted to approximately $95 \%$ original weight.

Surgery. Preparatory survival surgery was performed under isoflurane (0.5 to $2.5 \%)$ and aseptic conditions (Daberkow et al., 2013). Carprofen (5mg/kg s.c.) was administered as an analgesic. Rats were immobilized in a stereotaxic apparatus and holes for reference, stimulating, and recording electrodes and three screw holes were drilled. All stereotaxic coordinates were made in relation to bregma according to (Paxinos and Watson, 1986). The stimulating electrode was placed in the medial forebrain bundle (MFB; $-4.6 \mathrm{AP},+1.3$ ML, -7.5 DV). A recording electrode targeted the NAc (+1.3 AP, +1.5 ML, -6.5 DV). The $\mathrm{Ag} / \mathrm{AgCl}$ reference electrode was placed contralaterally in the superficial cortex. During surgery, the stimulating electrode was optimized, after which dental cement was used to fix the reference and stimulating electrode, and recording-electrode cannula positioned over the NAc. Following surgery, heparin was applied once daily to prevent blood clotting in the electrode cannula.

Electrochemistry. DA signals were recorded with FSCV at a CFM by applying a triangular waveform ( -0.4 to $+1.3 \mathrm{~V}$ and back) at a rate of $400 \mathrm{~V} / \mathrm{s}$ every $100 \mathrm{~ms}$. CFMs were fabricated in house by aspirating a single carbon fiber (HexTow AS4, HexCel 
Corp., Stamford, CT, USA) into a borosilicate capillary tube (1.2mm o.d.; Sutter Instrument, Novato, CA, USA) and pulling to a taper using a micropipette puller (Narishige, Tokyo, Japan). The carbon fiber was then cut to $~ 100$ microns distal to the glass-insulated seal. FSCV was performed by a Universal Electrochemistry Instrument (UEI; Department of Chemistry Electronic Shop, University of North Carolina, Chapel Hill, NC, USA) and commercially available software (ESA Bioscience, Chelmsford, MA, USA). Current recorded at peak oxidative potential for DA $(\sim+0.6 \mathrm{~V})$ was converted to DA concentration based on post-calibration of the CFM using flow-injection analysis with a modified TRIS buffer (Kume-Kick and Rice, 1998; Wu et al., 2001; Phillips et al., 2003). DA was identified from the background subtracted voltammogram (Michael et al., 1998; Heien et al., 2004).

Measurements with Electrical Stimulation. Electrical stimulation was computer generated and passed through an optical isolator and constant-current generator (Neurolog NL800; Digitimer Limited, Letchworth Garden City, UK). Biphasic stimulation pulses were applied to a twisted bipolar electrode (Plastics One, Roanoke, VA, USA); tips were separated $\sim 1 \mathrm{~mm}$. Stimulus parameters were a current of $\pm 125 \mu \mathrm{A}$ and a biphasic pulse duration of $4 \mathrm{~ms}$ ( $2 \mathrm{~ms}$ each phase), and trains were applied at a frequency of $60 \mathrm{~Hz}$ for $0.4 \mathrm{~s}$.

Unexpected Food Delivery. UFD was performed as previously described (Brown et al., 2011b). In brief, prior to surgery, rats were food restricted and given two sessions (one per day) to retrieve food-pellets in a standard operant chamber (Med Associates). During this magazine training single food pellets were delivered at a variable inter-trial interval (range 30-90 seconds; average 60 second inter-trial interval; 30 trials). After 
surgery, rats received one additional magazine training with the headstage attached. The following day, a CFM was lowered and optimized for both food evoked and electrically evoked DA signals. DA was recorded with FSCV. After optimization, electrically evoked DA signals were collected pre-drug following 10 minutes of habituation followed by a UFD paradigm, which has identical parameters as the magazine training sessions. After UFD, rats were administered saline or ATX (1 or $10 \mathrm{mg} / \mathrm{kg}$ i.p.), followed by 10 minutes of habituation and a final UFD paradigm. After the second UFD, electrically evoked phasic-like DA signals were collected. 


\section{Results}

Atomoxetine Inhibits Food-Pellet Consumption. Our results suggest that all rats administered ATX (10 mg/kg) became anorexic (data not shown). Animals were considered anorexic if all food-pellets were not consumed during the final session of UFD.

\section{Atomoxetine Diminishes Electrically Evoked Phasic-Like Dopamine Signals.} Figure 12 shows average effects of $\operatorname{ATX}(n=4)$ on electrically evoked phasic-like DA signals. Maximal signal amplitude is expressed as a ratio of DA elicited post-drug/predrug. Our results suggest that ATX diminished electrically evoked phasic-like DA signals. Changes in the electrically evoked phasic-like DA signal amplitude are potentially mediated by DA release and/or uptake (Wu et al., 2001); however, potential presynaptic effects of ATX have yet to be investigated.

\section{Atomoxetine Reduces Food-Evoked Dopamine Transients. Figure 13 shows} saline (A) and ATX (B) representative effects on food-evoked DA transients. Saline (A) showed no effect on food-evoked DA transients (pre-drug, left; post-drug, right). The top of each panel shows DA concentration collected as the current recorded at the peak oxidative potential for DA and converted to concentration by post-calibration. Pseudocolor plots below showing sequential voltammograms and individual voltammograms (inset) identify DA as the primary analyte elicited initially by UFD by its electrochemical profile. ATX (B) in this representative example appears to entirely prevent the foodevoked DA transient. Average $(n=4)$ effects of ATX on food-evoked DA transients $(C)$. Similar to the representative data, ATX strongly decreased the amplitude of food-evoked DA transients expressed as a ratio of post-drug/pre-drug transients. 


\section{Future Directions}

Our preliminary results suggest that ATX alters phasic DA signaling; however, further investigation of its effects are warranted. First, the surprising effect of ATX on electrically evoked phasic-like DA signals will be investigated by assessing presynaptic mechanisms of DA release and DA uptake. Additionally, the effects of ATX will be examined on spontaneous DA transients by analyzing effects of ATX on transient frequency, amplitude and duration. Lastly, a lower behaviorally relevant dose of ATX (1 $\mathrm{mg} / \mathrm{kg}$ ) will be investigated. As dose plays an important role in drug efficacy (Berridge and Stalnaker, 2002), investigation of ATX at various doses is valuable in identifying potentially different mechanisms of action. 


\section{REFERENCES}

Alvarez JA, Emory E (Executive function and the frontal lobes: a meta-analytic review. Neuropsychol Rev 16:17-42.2006).

American Psychiatric Association. DSM-V: Diagnostic and statistical manual of mental disorders (5th edn). 2013. Washington, D.C.

Antrop I, Stock P, Verte S, Wiersema JR, Baeyens D, Roeyers H (ADHD and delay aversion: the influence of non-temporal stimulation on choice for delayed rewards. J Child Psychol Psychiatry 47:1152-1158.2006).

Arnsten AF, Pliszka SR (Catecholamine influences on prefrontal cortical function: relevance to treatment of attention deficit/hyperactivity disorder and related disorders. Pharmacol Biochem Behav 99:211-216.2011).

Avelar AJ, Juliano SA, Garris PA (Amphetamine augments vesicular dopamine release in the dorsal and ventral striatum through different mechanisms. J Neurochem 125:373-385.2013).

Berridge CW, Stalnaker TA (Relationship between low-dose amphetamine-induced arousal and extracellular norepinephrine and dopamine levels within prefrontal cortex. Synapse.2002).

Booth JR, Burman DD, Meyer JR, Lei Z, Trommer BL, Davenport ND, Li W, Parrish TB, Gitelman DR, Mesulam MM (Larger deficits in brain networks for response inhibition than for visual selective attention in attention deficit hyperactivity disorder (ADHD). J Child Psychol Psychiatry 46:94-111.2005).

Brown HD, McCutcheon JE, Cone JJ, Ragozzino ME, Roitman MF (Primary food reward and reward predictive stimuli evoke different patterns of phasic dopamine signaling throughout the striatum. Eur J Neurosci 34:1997-2006.2011a).

Brown HD, McCutcheon JE, Cone JJ, Ragozzino ME, Roitman MF (Primary food reward and reward-predictive stimuli evoke different patterns of phasic dopamine signaling throughout the striatum. Eur J Neurosci 34:1997-2006.2011b).

Bymaster FP, Katner JS, Nelson DL, Hemrick-Luecke SK, Threlkeld PG, Heiligenstein $\mathrm{JH}$, Morin SM, Gehlert DR, Perry KW (Atomoxetine increases extracellular levels of norepinephrine and dopamine in prefrontal cortex of rat: a potential mechanism for efficacy in attention deficit/hyperactivity disorder. Neuropsychopharmacology 27:699-711.2002).

Correia Filho AG, Bodanese R, Silva TL, Alvares JP, Aman M, Rohde LA (Comparison of risperidone and methylphenidate for reducing ADHD symptoms in children 
and adolescents with moderate mental retardation. J Am Acad Child Adolesc Psychiatry 44:748-755.2005).

Daberkow DP, Brown HD, Bunner KD, Kraniotis SA, Doellman MA, Ragozzino ME, Garris PA, Roitman MF (Amphetamine paradoxically augments exocytotic dopamine release and phasic dopamine signals. J Neurosci 33:452-463.2013).

Darracq L, Blanc GF, Glowinski JF, Tassin JP (Importance of the noradrenalinedopamine coupling in the locomotor activating effects of D-amphetamine. J Neurosci.1998).

Day JJ, Roitman MF, Wightman RM, Carelli RM (Associative learning mediates dynamic shifts in dopamine signaling in the nucleus accumbens. Nat Neurosci 10:1020-1028.2007).

Grace AA, Bunney BS (The control of firing pattern in nigral dopamine neurons: burst firing. J Neurosci 4:2877-2890.1984).

Heien ML, Johnson MA, Wightman RM (Resolving neurotransmitters detected by fastscan cyclic voltammetry. Anal Chem 76:5697-5704.2004).

Ince TB, Karakaya E, Oztop DB (Effects of Atomoxetine and Osmotic Release Oral System-Methylphenidate on Executive Functions in Patients with Combined Type Attention-Deficit/Hyperactivity Disorder. J Child Adolesc Psychopharmacol 25:494-500.2015).

James RS, Sharp WS, Bastain TM, Lee PP, Walter JM, Czarnolewski M, Castellanos FX (Double-blind, placebo-controlled study of single-dose amphetamine formulations in ADHD. J Am Acad Child Adolesc Psychiatry 40:1268-1276.2001).

Jasinski DR, Faries DE, Moore RJ, Schuh LM, Allen AJ (Abuse liability assessment of atomoxetine in a drug-abusing population. Drug Alcohol Depend 95:140146.2008).

Kratochvil CJ, Newcorn JH, Arnold LE, Duesenberg D, Emslie GJ, Quintana H, Sarkis $\mathrm{EH}$, Wagner KD, Gao H, Michelson D, Biederman J (Atomoxetine alone or combined with fluoxetine for treating ADHD with comorbid depressive or anxiety symptoms. J Am Acad Child Adolesc Psychiatry 44:915-924.2005).

Kuczenski R, Segal DS (Locomotor effects of acute and repeated threshold doses of amphetamine and methylphenidate: relative roles of dopamine and norepinephrine. J Pharmacol Exp Ther 296:876-883.2001).

Kuczenski R, Segal DS (Exposure of adolescent rats to oral methylphenidate: preferential effects on extracellular norepinephrine and absence of sensitization and crosssensitization to methamphetamine. J Neurosci.2002).

Kume-Kick J, Rice ME (Dependence of dopamine calibration factors on media $\mathrm{Ca} 2+$ and $\mathrm{Mg} 2+$ at carbon-fiber microelectrodes used with fast-scan cyclic voltammetry. $\mathrm{J}$ Neurosci Methods 84:55-62.1998). 
Michael D, Travis ER, Wightman RM (Color images for fast-scan CV measurements in biological systems. Anal Chem 70:586A-592A.1998).

Newcorn JH, Kratochvil CJ, Allen AJ, Casat CD, Ruff DD, Moore RJ, Michelson D (Atomoxetine and osmotically released methylphenidate for the treatment of attention deficit hyperactivity disorder: acute comparison and differential response. Am J Psychiatry 165:721-730.2008).

Paxinos G, Watson C (1986) The rat brain in stereotaxic coordinates. New York: Academic Press.

Phillips PE, Robinson DL, Stuber GD, Carelli RM, Wightman RM (Real-time measurements of phasic changes in extracellular dopamine concentration in freely moving rats by fast-scan cyclic voltammetry. Methods Mol Med 79:443464.2003).

Polanczyk GV, Willcutt EG, Salum GA, Kieling C, Rohde LA (ADHD prevalence estimates across three decades: an updated systematic review and meta-regression analysis. Int J Epidemiol 43:434-442.2014).

Rubia K, Smith AB FAU - Brammer M, Brammer MJ FAU - Toone B, Toone BF, Taylor $\mathrm{E}$ (Abnormal brain activation during inhibition and error detection in medicationnaive adolescents with ADHD. Am J Psychiatry.2005).

Scheres A, Milham MP, Knutson B, Castellanos FX (Ventral striatal hyporesponsiveness during reward anticipation in attention-deficit/hyperactivity disorder. Biol Psychiatry 61:720-724.2007).

Schultz W (Dopamine neurons and their role in reward mechanisms. Curr Opin Neurobiol 7:191-197.1997).

Schultz W, Dayan P, Montague PR (A neural substrate of prediction and reward. Science 275:1593-1599.1997).

Shi WX, Pun CL, Zhang XX, Jones MD, Bunney BS (Dual effects of D-amphetamine on dopamine neurons mediated by dopamine and nondopamine receptors. J Neurosci 20:3504-3511.2000).

Shi WX, Pun CL, Zhou Y (Psychostimulants induce low-frequency oscillations in the firing activity of dopamine neurons. Neuropsychopharmacology 29:21602167.2004).

Sonuga-Barke EJ (The dual pathway model of AD/HD: an elaboration of neurodevelopmental characteristics. Neurosci Biobehav Rev 27:593-604.2003).

Tidey JW, Bergman J (Drug discrimination in methamphetamine-trained monkeys: agonist and antagonist effects of dopaminergic drugs. J Pharmacol Exp Ther 285:1163-1174.1998).

Tripp G, Wickens JR (Research review: dopamine transfer deficit: a neurobiological theory of altered reinforcement mechanisms in ADHD. J Child Psychol Psychiatry.2008). 
Tzavara ET, Bymaster FP, Overshiner CD, Davis RJ, Perry KW, Wolff M, McKinzie DL, Witkin JM, Nomikos GG (Procholinergic and memory enhancing properties of the selective norepinephrine uptake inhibitor atomoxetine. Mol Psychiatry 11:187-195.2006).

Wu Q, Reith ME, Wightman RM, Kawagoe KT, Garris PA (Determination of release and uptake parameters from electrically evoked dopamine dynamics measured by real-time voltammetry. J Neurosci Methods 112:119-133.2001). 


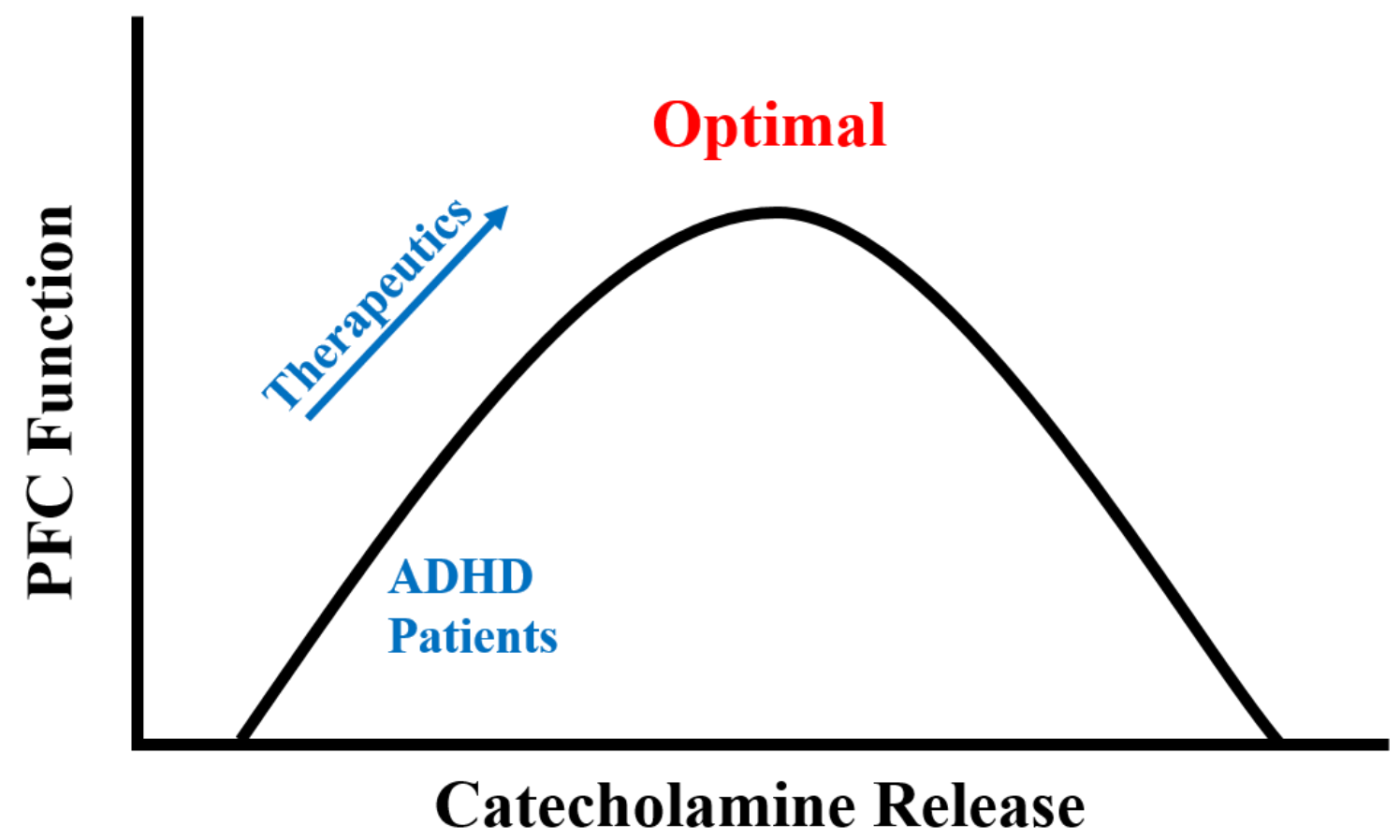

Figure 9. Inverted-U model of attention deficit hyperactivity disorder. Optimal catecholamine release results in optimal PFC function. ADHD patients are thought to exhibit low catecholamine release and concomitantly low PFC function. Therapeutic drugs for ADHD enhance catecholamine release and thereby enhance PFC function in ADHD patients. 


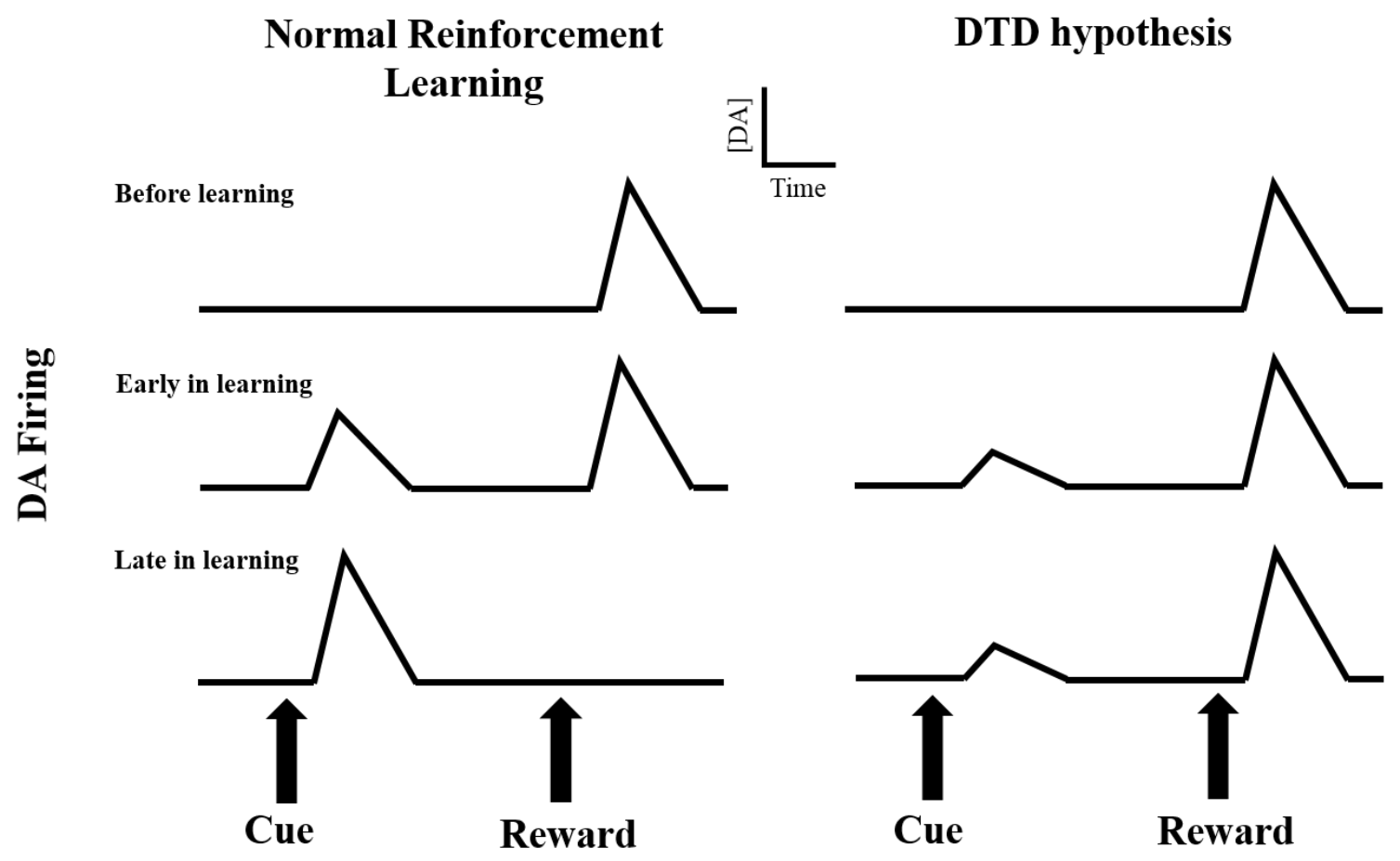

Figure 10. Reinforcement learning and dopamine function. Phasic DA signaling is activated after rewards and cues predicting their rewards. Before reward-prediction learning, phasic DA signals are activated by rewards and not to the presentation of the cue. In early learning phasic DA signaling is activated by cue onset and reward delivery. Finally, late in learning, phasic DA signaling transfers from the reward to the cue. In ADHD patients, the DTD theory proposes that the transfer of phasic Da signaling from the reward to the cue is incomplete resulting in altered reinforcement learning. 


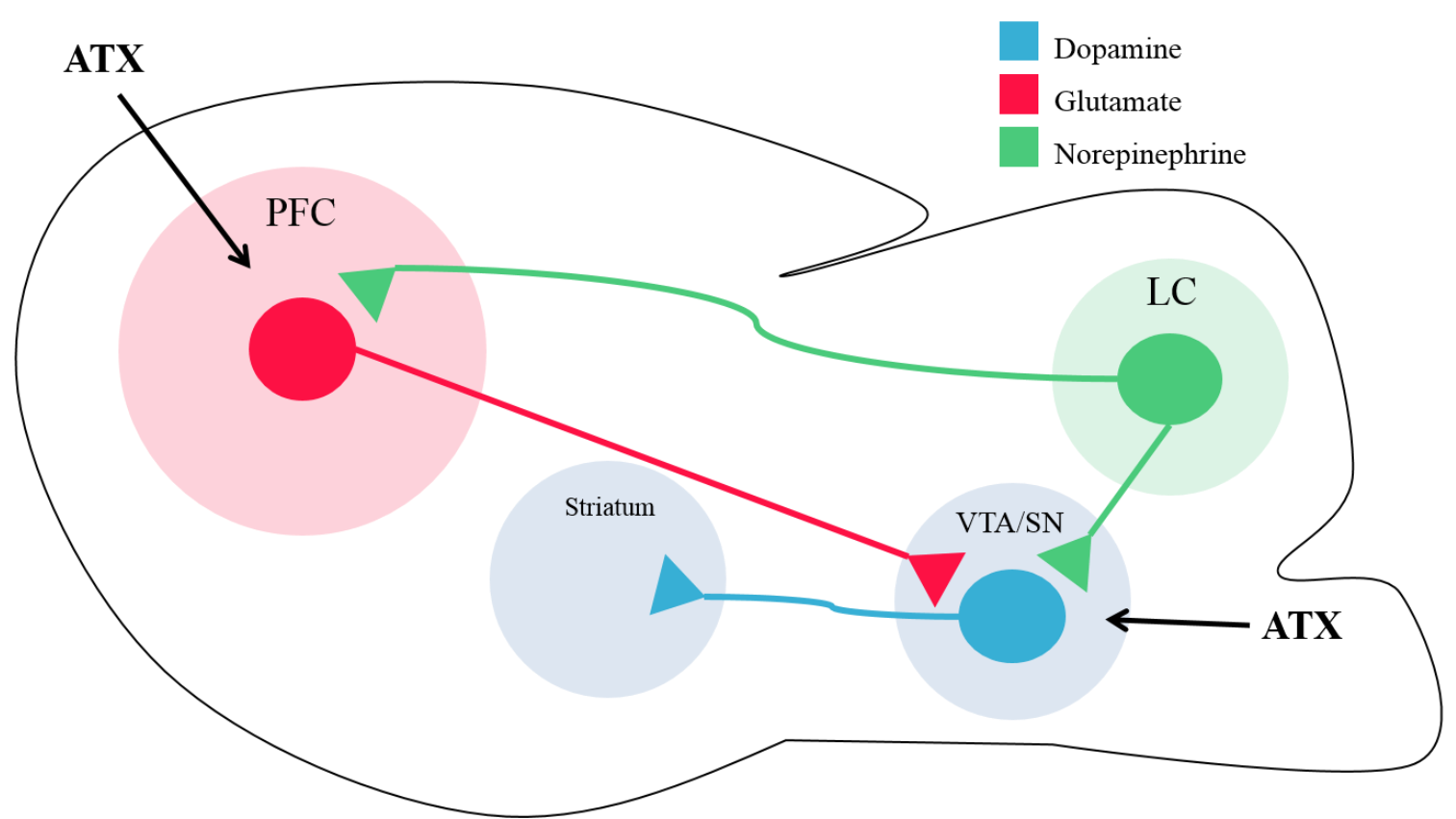

Figure 11. Afferent input and midbrain dopamine neurons. Projections from the PFC and LC terminate on midbrain DA neurons and alter DA signaling. NE cell bodies originate in the LC and project to the PFC and to midbrain DA neurons, which originate in the VTA and SN. In the PFC, glutamate axons project to midbrain DA neurons. In the midbrain, DA axons project to both the striatum and PFC. Abbreviations: PFC, prefrontal cortex; DS, dorsal striatum; SN, substantia nigra; VTA, ventral tegmental area; LC, locus coeruleus. 


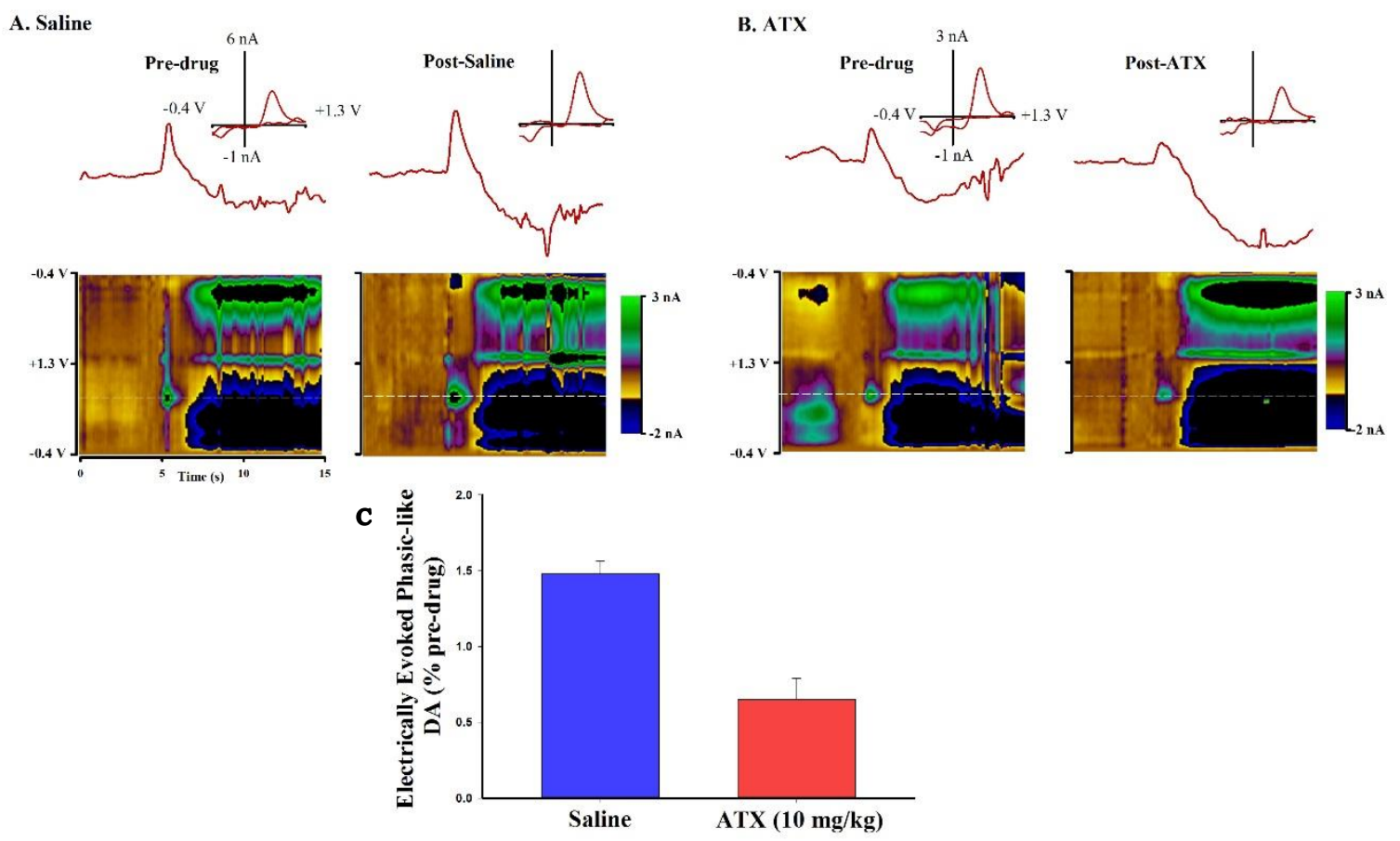

Figure 12. Atomoxetine decreases amplitude of electrically evoked phasic-like dopamine signals. Traces show increased [DA] after electrical stimulation at $5 \mathrm{~s}$. Color plots below and voltammograms (inset) identify DA as primary analyte. Saline (A) shows slight increase in electrically evoked phasic-like [DA] (A: right) compared to pre-drug (A: left). ATX (B: right) shows decrease in electrically evoked [DA] compared to pre-drug (B: left). Below (C) shows average electrically evoked phasic-like DA amplitude expressed as a ratio of post-drug over pre-drug and are mean \pm SEM. Saline: $n=2$; ATX: $n=4$. 


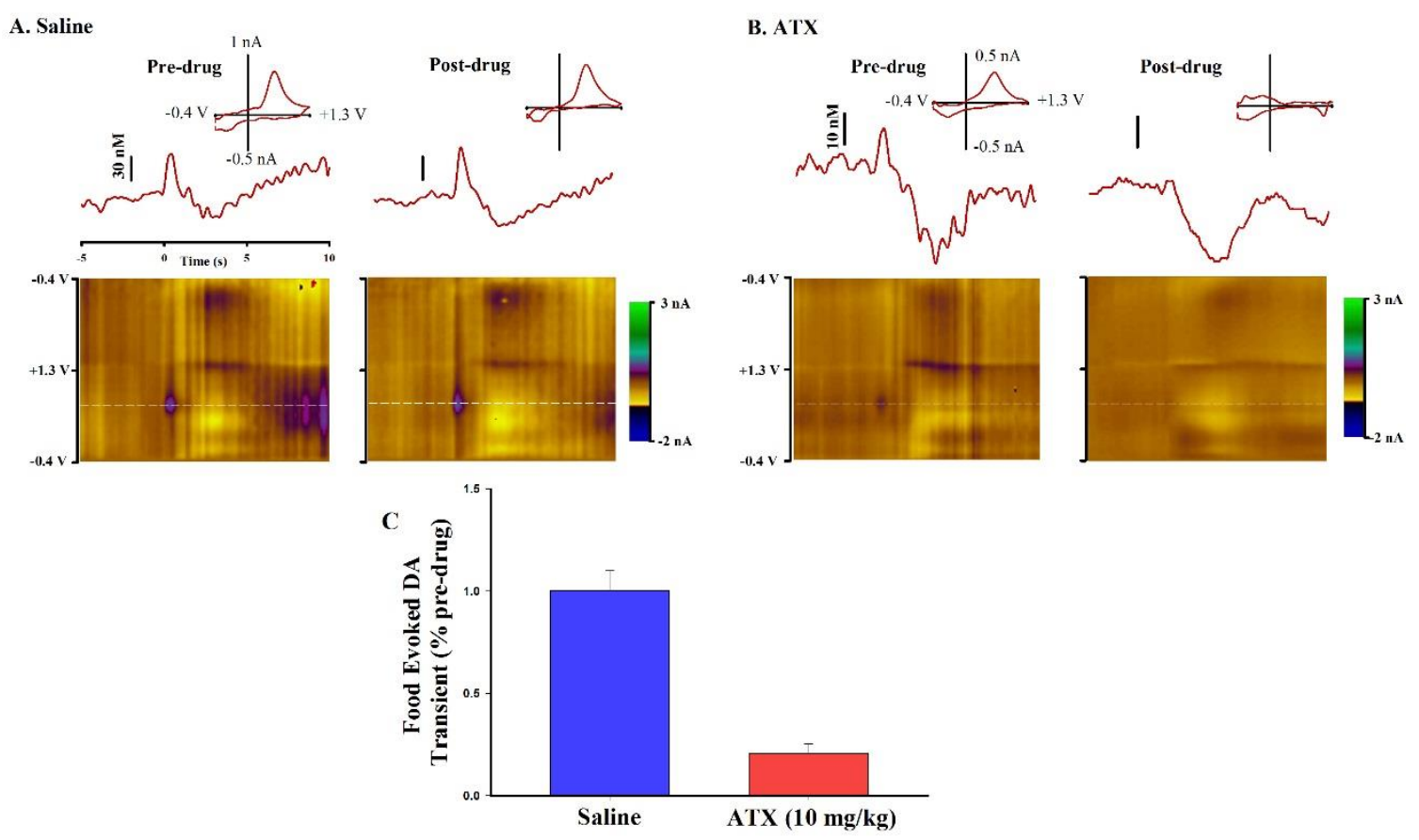

Figure 13. Atomoxetine decrease food-evoked dopamine transients. Representative saline (A) and ATX (10 mg/kg) (B) effects on Food-evoked DA transients. Average color plots of raw FSCV data illustrating the effect on unexpected food delivery before (left) and of (right) saline (A) and ATX (B). (Top) DA transients elicited by unexpected food delivery (left) and post-drug (right) taken at peak oxidation potential of DA (white dashed line). INSET: individual voltammogram taken from peak signal amplitude identifying the analyte as DA. Average effects of ATX and saline on Food-evoked DA transients (C). Data are expressed as a ratio of post-drug over pre-drug and are mean \pm SEM. Saline: $\mathrm{n}=3$; ATX: $\mathrm{n}=4$. Saline: $\mathrm{n}=3$; ATX: $\mathrm{n}=4$. 